Prepared for the U.S. Department of Energy

under Contract DE-AC05-76RL01830

\title{
Commercial Building Partnerships Replication and Diffusion
}

CA Antonopoulos

HE Dillon

MC Baechler

September 2013

Pacific Northwest

NATIONAL LABORATORY

Proudly Operated by Battelle Since 1965 


\title{
DISCLAIMER
}

This report was prepared as an account of work sponsored by an agency of the United States Government. Neither the United States Government nor any agency thereof, nor Battelle Memorial Institute, nor any of their employees, makes any warranty, express or implied, or assumes any legal liability or responsibility for the accuracy, completeness, or usefulness of any information, apparatus, product, or process disclosed, or represents that its use would not infringe privately owned rights. Reference herein to any specific commercial product, process, or service by trade name, trademark, manufacturer, or otherwise does not necessarily constitute or imply its endorsement, recommendation, or favoring by the United States Government or any agency thereof, or Battelle Memorial Institute. The views and opinions of authors expressed herein do not necessarily state or reflect those of the United States Government or any agency thereof.

\author{
PACIFIC NORTHWEST NATIONAL LABORATORY \\ operated by \\ BATTELLE \\ for the \\ UNITED STATES DEPARTMENT OF ENERGY \\ under Contract DE-AC05-76RL01830
}

Printed in the United States of America
Available to DOE and DOE contractors from the Office of Scientific and Technical Information,
P.O. Box 62, Oak Ridge, TN 37831-0062;
ph: (865) 576-8401
fax: $(865)$ 576-5728
email: reports@adonis.osti.gov

\begin{abstract}
Available to the public from the National Technical Information Service, U.S. Department of Commerce, 5285 Port Royal Rd., Springfield, VA 22161 ph: (800) 553-6847 fax: $(703) 605-6900$ email: orders@ntis.fedworld.gov online ordering: http://www.ntis.gov/ordering.htm
\end{abstract}

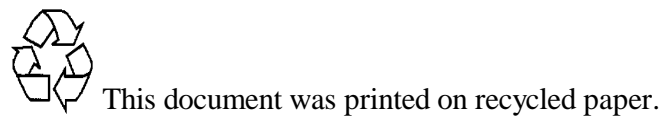




\section{Commercial Building Partnerships Replication and Diffusion}

CA Antonopoulos, HE Dillon and MC Baechler

September 2013

Prepared for U.S. Department of Energy

Pacific Northwest National Laboratory

Richland, Washington 99352 


\section{Executive Summary}

This study presents findings from questionnaire and interview data investigating replication efforts of Commercial Building Partnership (CBP) partners that worked directly with the Pacific Northwest National Laboratory (PNNL). PNNL partnered with 12 organizations on new and retrofit construction projects as part of the U.S. Department of Energy (DOE) CBP program. PNNL and other national laboratories collaborate with industry leaders that own large portfolios of buildings to develop high performance projects for new construction and renovation. This project accelerates market adoption of commercially available energy saving technologies into the design process for new and upgraded commercial buildings. The labs provide assistance to the partners' design teams and make a business case for energy investments. From the owner's perspective, a sound investment results in energy savings based on corporate objectives and design.

PNNL's partners manage a variety of building types. These included a large existing office building, bank branches, retail stores, malls, lodging, higher education buildings, and a military training center. Only building owners or managers that participated in all of five CBP stages were included in this study. A number of partners had projects that were unable to be completed within the scope of the CBP and were not included in this study.

Through a feedback questionnaire, along with personal interviews, PNNL gathered qualitative and quantitative information relating to replication efforts by each organization. Data through this process were analyzed to provide insight into two primary research areas: 1) CBP partners' replication efforts of technologies and approaches used in the CBP project to the rest of the organization's building portfolio (including replication verification), and, 2) the market potential for technology diffusion into the total U.S. commercial building stock, as a direct result of the CBP entire program.

The first area of this research focused specifically on replication efforts underway or planned by each CBP program participant. Factors that impact replication include motivation, organizational structure and objectives firms have for implementation of energy efficient technologies. Comparing these factors among different CBP partners revealed patterns in motivation for constructing energy-efficient buildings, along with better insight into market trends for green building practices. This investigation included two steps. First, partners were asked to complete an online questionnaire. Second, each partner was interviewed to gain more in-depth information on their organization's actions and plans. All but one partner participated in the questionnaire and follow-up conversation.

Primary conclusions of the CBP partner replication analysis include:

- The CBP program provided an optimized approach to implementing energy efficiency measures (EEMs) for cost and energy savings. This differs from other green building programs, which require a checklist-type system of prescriptive or benchmark requirements.

- $100 \%$ of CBP partners contacted for this study indicated they would replicate some or all energy efficiency measures (EEMs) and CBP approaches.

- Three EEMs, (low wattage exit signs, occupancy sensors and energy management systems), have a $100 \%$ replication rate.

- Lighting and heating, ventilation and air conditioning (HVAC) technologies were most broadly adopted by CBP partners. 
- Six partners confirmed that light emitting diode (LED) lighting technology and design will now be used in their building portfolios thanks to participation in the CBP program.

- The CBP program provided a testbed for future energy efficiency projects (new and existing building) within the partner portfolio.

- CBP partners are motivated by cost savings more than other benefits.

In the interviews conducted after the questionnaires were completed, the following takeaways were identified by CBP partners regarding specific measures or implementation strategies partners intend to replicate based on their experience with the CBP program:

- Two partners indicated that they now have a detailed plan for measurement and verification $(\mathrm{M} \& \mathrm{~V})$ programs that will be rolled out to all building engineers within the organization.

- One partner indicated significant savings potential from reducing plug loads, an area that was not focused on before participation in the CBP program.

- One partner indicated that the entire package of CBP EEMs will be replicated in all new and existing buildings owned by the organization.

- Three partners indicated that LEED standards are mandated in all new construction. Takeaways from the CBP program will be added to their existing protocol.

- Three partners indicated that enhanced modeling and optimizing an EEM package that included climate zone considerations were primary takeaways from program participation.

In addition, PNNL staff offer the following observations. These points are not discussed as part of this investigation but have been described in earlier work (Rahul, 2011; Xie, 2011; Baechler, 2011).

- Partners with large portfolios did not make hard and fast distinctions between new and existing buildings. Within the partner's corporate structure, different groups manage renovation versus new construction. However, EEMs from one building type are readily transferred across all building types.

- Much of the assistance provided by PNNL involved advanced building simulation that required thoughtful characterization of the building, identification of appropriate EEMs, and a thoroughly integrated design process. The information sharing, joint investigations, and collaboration both within the design team and across corporate organizations often resulted in innovative ideas and long term commitments to pursue EEMs.

The second portion of this study uses the diffusion of innovations theory to explore possible market impacts of the CBP program throughout the commercial building sector in the United States. Diffusion models are widely used in many industries as a means to describe the process of technical change and advancement of innovation within a culture over time (Rogers, 1995). Analysis of CBP partners' replication efforts across their building portfolios provided foundations for broader market analysis of the potential of the CBP program on total commercial building sector energy consumption and cost savings.

For the CBP buildings, the diffusion of innovations theory is based on the model developed by Frank Bass (Bass, 1969). This analysis of CBP treats diffusion of the entire energy-efficient building as a single technology rather than individual EEMs. To determine the correct coefficients for the model, the market penetration of green buildings was considered using the data available for other energy efficiency programs similar to CBP.

The final Bass model parameters predict a range of diffusion scenarios. The maximum diffusion of CBP methods is predicted to impact almost 100,000 buildings by 2030 . The conservative diffusion model based only on the DOE CBP data predicts an impact of about 2,900 buildings by 2030 . The figure below 
shows the two Bass models and raw data on the same scale. Two Bass models (CBP Construction and Market Bass Model) were developed which resulted in a large difference between modeled outputs. The CBP Construction model (conservative) was developed using data from CBP partners only, with the output representing the maximum number of buildings impacted normalized by the total number of buildings in CBP partner portfolios. The Market Bass model (optimistic) was developed by extrapolating the dataset out to the broader market, and represents market diffusion potential for the full partner portfolios based on the observed diffusion of other green building programs. The third curve, CBP Construction, represents the raw CBP data (actual) tracking partner building projects.

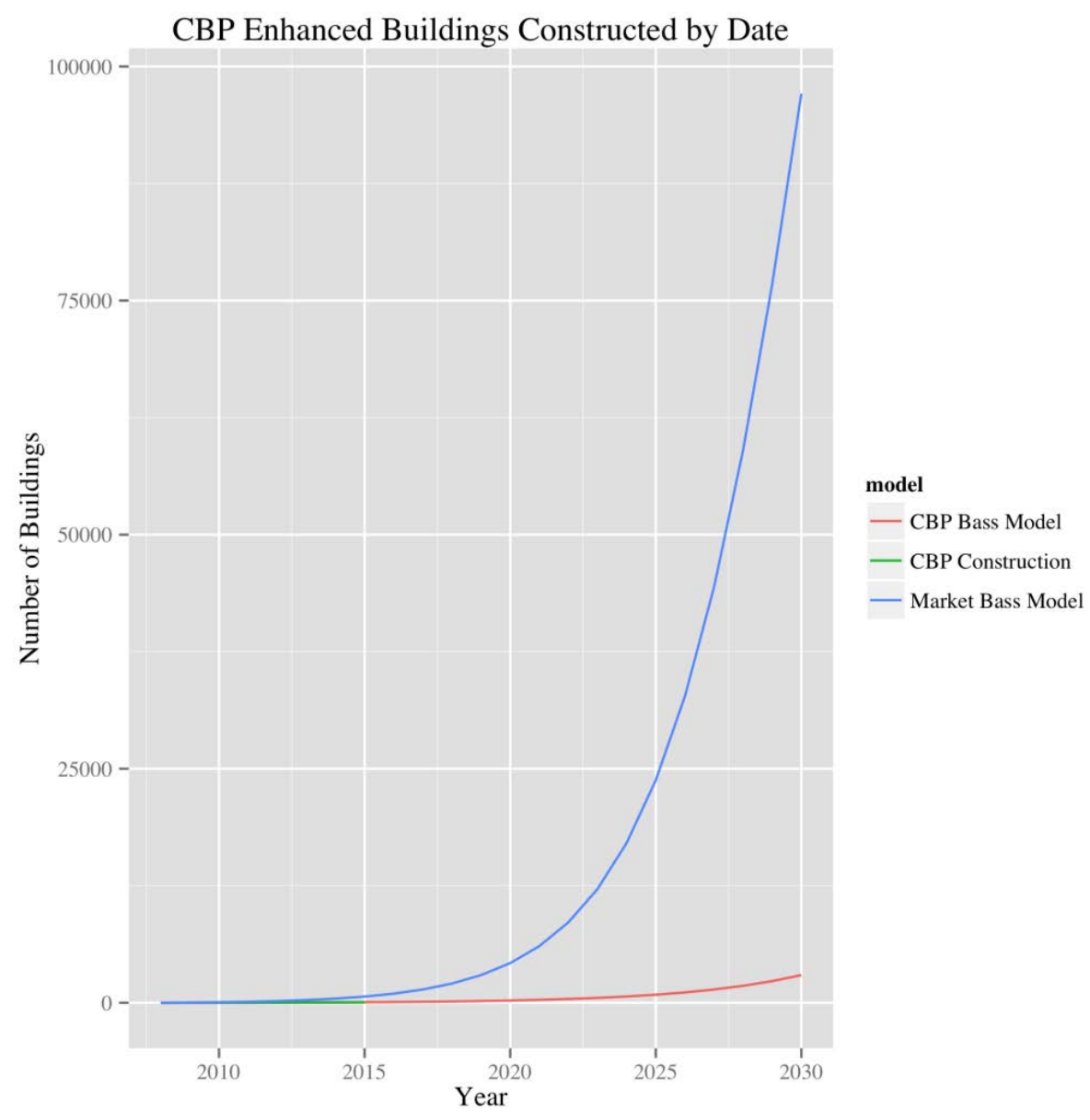

Figure 1. CBP Market Penetration Prediction Using the Bass Model

The maximized diffusion model was validated using a larger data set from the U.S. Green Building Council (USGBS) and agrees well with existing data on energy efficiency program penetration. The conclusion from the analysis of the Bass model when applied to the USGBC database is that this method of prediction may be used to adequately capture cumulative construction metrics for whole building energy efficiency programs. The Bass model parameters also provide an optimistic perspective for the type of market diffusion that may occur based on historic energy efficiency programs.

By 2030, the diffusion model forecasts a range between about 3,000 and 100,000 buildings will be impacted by the CBP program through partner replication efforts. This translates to approximately 43.5 million to 1.4 billion square feet of commercial building floor space. Previous analytical efforts of CBP projects modeled energy use intensity (EUI) reductions of $53 \mathrm{kBtu} / \mathrm{ft}^{2}$ for new construction projects 
overseen by PNNL (Baechler et al., 2012). In an effort to extrapolate broader energy savings data, the research team compared this decrease in modeled CBP EUIs with median EUI data from CBECS and ENERGY STAR. Based on this analysis, the energy savings potential in 2030 is between 2.3 and 77 trillion Btus annually of site energy consumption.

The results of the diffusion model, the questionnaire, and the partner interviews suggest that the CBP effort may successfully catalyze the adoption of significant energy efficiency measures in major subsectors of the commercial building population. The nature of the program provided a mechanism for effectively targeting the cost driver among many of the partners. The energy savings in the next several decades will continue to increase as more CBP enhanced buildings become operational. 


\section{Table of Contents}

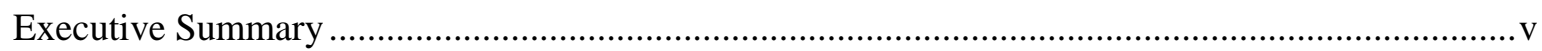

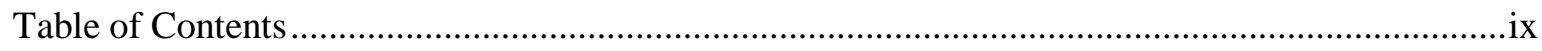

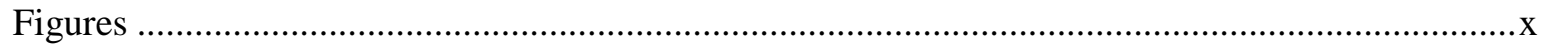

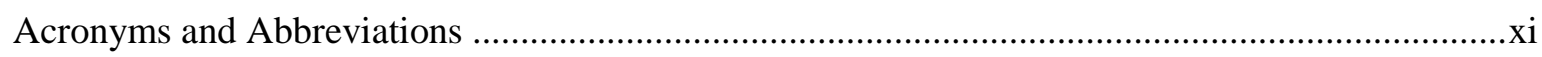

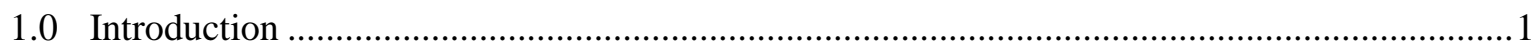

1.1 The Commercial Building Partnership Program .........................................................

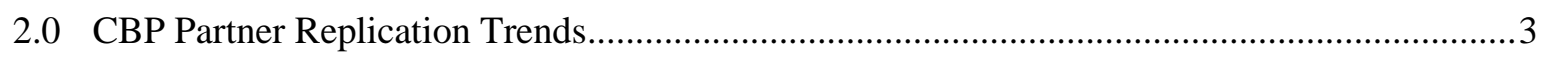

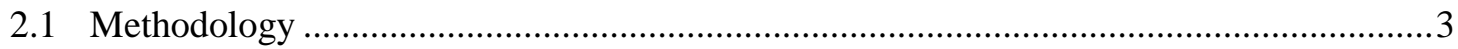

2.2 Overview of CBP Participant Characteristics …........................................................

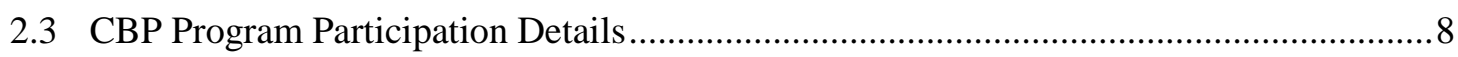

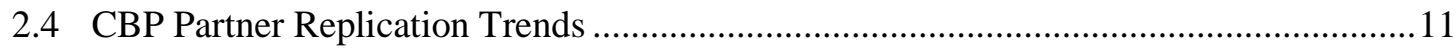

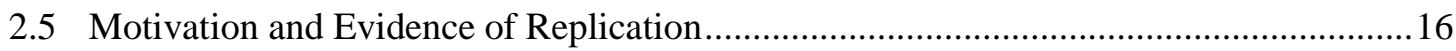

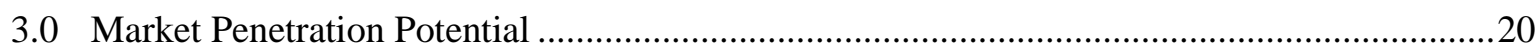

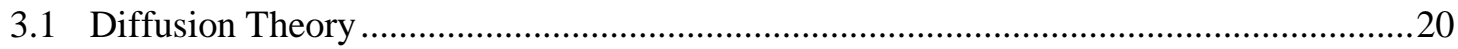

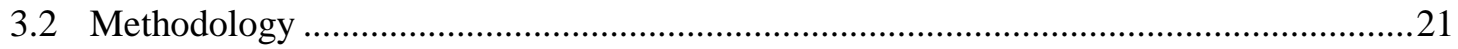

3.2.1 Energy Efficiency Building Diffusion Data with Bass Model.............................22

3.2.2 Application of the Bass Diffusion Model to CBP …..........................................25

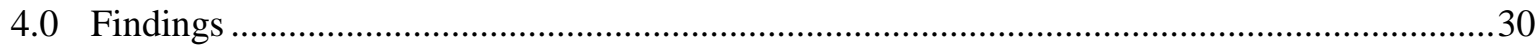

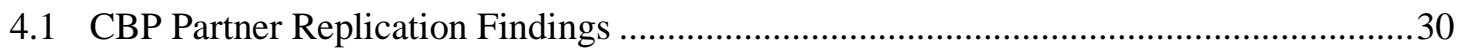

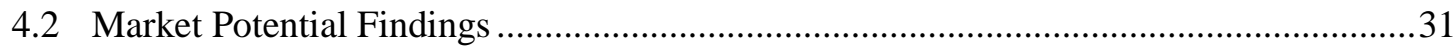

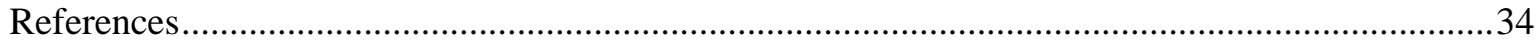

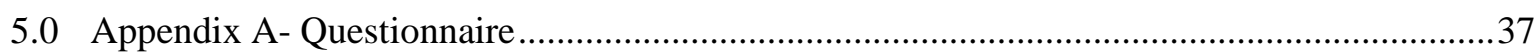




\section{Figures}

Figure 1. CBP Market Penetration Prediction Using the Bass Model ..............................................vii

Figure 2. CBP Partner Participation by Industry as Reported by Questionnaire Respondents $(\mathrm{N}=9)$

Figure 3. CBP Partner Program Participation Before, During or After their CBP Building Project, by Percentage of Questionnaire Participation (Multiple Responses Allowed) ...........................6

Figure 4. Percentage of CBP Projects by Building Type (N=9) ................................................

Figure 5. Current Phase of Construction for Each CBP Partner ................................................... 8

Figure 6. CBP Partner Forecast Energy Savings for the CBP Building in the Next 5-10 Years as

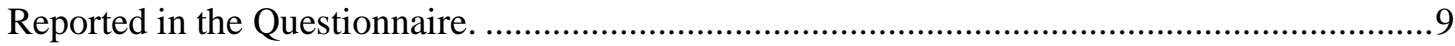

Figure 7. CBP Partner Forecast Cost Savings for the CBP Building in the Next 5-10 Years as

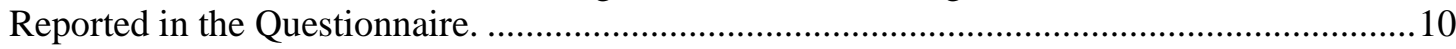

Figure 8. CBP Partner Forecast Energy Savings for the Partner Portfolio in the Next 5-10 Years

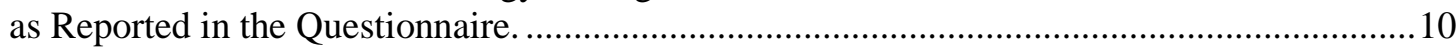

Figure 9. CBP Partner Reported Number of Buildings with Replication at the Time of the Questionnaire 12

Figure 10. CBP Partner Reported EEMs by Type and Building Sector....................................... 14

Figure 11. Economic Metrics used by CBP Partners to Measure EEM Cost Effectiveness ............ 16

Figure 12. Percentage of Organizations with Policies/Procedures for EEM Implementation ..........17

Figure 13. Questionnaire Responses to CBP Benefits beyond Energy and Cost Savings. Respondents Ranked the Benefits and Percentage of Responses are Shaded........................... 18

Figure 14. Traditional Diffusion Curve (Patenaude, 2011) .......................................................20

Figure 15. Raw Diffusion Data and the Yudelson Model........................................................23

Figure 16. Raw Diffusion Data and the Bass Model Fit for Our Study .......................................25

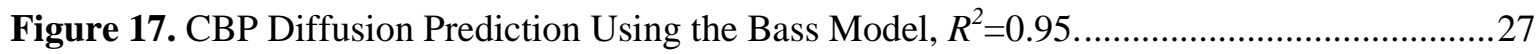




\section{Acronyms and Abbreviations}

\begin{tabular}{|c|c|}
\hline ANL & Argonne National Laboratory \\
\hline ANSI & American National Standards Institute \\
\hline ARRA & American Recovery and Reinvestment Act \\
\hline ASHRAE & American Society of Heating, Refrigerating and Air-Conditioning Engineers \\
\hline BLCC & building life-cycle cost analysis \\
\hline BTO & Building Technologies Office \\
\hline Btu & British thermal unit \\
\hline CBECS & Commercial Building Energy Consumption Survey \\
\hline CBP & Commercial Building Partnerships \\
\hline CSR & corporate social responsibility \\
\hline DOE & U.S. Department of Energy \\
\hline EEM & energy efficiency measure \\
\hline EERE & Energy Efficiency and Renewable Energy Office \\
\hline EIA & U.S. Energy Information Administration \\
\hline EUI & energy use intensity \\
\hline GDP & gross domestic product \\
\hline HVAC & heating, ventilation and air-conditioning \\
\hline IESNA & Illuminating Engineering Society of North America \\
\hline $\mathrm{kWh}$ & kilowatt hour \\
\hline LBNL & Lawrence Berkeley National Laboratory \\
\hline LCC & life-cycle cost analysis \\
\hline LED & light emitting diode \\
\hline LEED & Leadership in Energy and Environmental Design \\
\hline
\end{tabular}


NREL National Renewable Energy Laboratory

O\&M operations and maintenance

PNNL Pacific Northwest National Laboratory

ROI return on investment

SIR savings to investment ratio

USGBC U.S. Green Building Council

VFD variable frequency drive 


\subsection{Introduction}

In 2010, the U.S. consumed 97 quadrillion Btus of energy, spending approximately $\$ 1.2$ trillion, or roughly $8.3 \%$ of total gross domestic product (GDP) for the country (EIA, 2012). In 2011, U.S. energy consumption resulted in approximately 5.5 billion metric tons of carbon dioxide emitted into the atmosphere (EIA, 2012). U.S. energy consumption equals approximately $19 \%$ of global consumption; a close second only to China which consumes $20 \%$ of global totals (DOE, 2012a). While energy production and consumption is essential for U.S. economic interests, there are increasingly negative environmental externalities, as well as continuing threats to national security.

Of the overall energy footprint in the U.S., approximately $40 \%$ of total primary energy is consumed by the buildings sector, almost half of which is attributed to commercial buildings (DOE, 2012a).

Furthermore, building codes, which mandate benchmark safety and building procedures, did not include energy savings considerations before 1979. According to the most recent Commercial Building Energy Consumption Survey (CBECS), there were approximately 4.9 million commercial buildings in the U.S. in 2003, 2.8 million of which were built prior to 1979, when the first energy codes were enacted (EIA, 2008). Building energy codes help address energy losses through prescriptive requirements for envelope, mechanical and electrical system efficiencies, thus promoting efficient systems and lowering the overall footprint of the building.

The United States has ambitious goals for increasing efficiency of the nation's building stock and lowering the energy footprint of both residential and commercial buildings. The U.S. Department of Energy (DOE) has commercial building reduction goals of $20 \%$ by 2020 , supported by programs through Energy Efficiency and Renewable Energy's (EERE) Building Technologies Office (BTO). By 2030, all federal buildings are required to meet a 30\% reduction in energy intensity based on 2003 levels (DOE, 2011a). To promote energy efficiency in the buildings sector, EERE utilizes a multi-pronged effort that includes research to develop new energy efficient building technologies, regulatory efforts to enforce greater efficiency for new buildings and equipment, and deployment programs that seek to promote adoption of energy efficient technologies in new and existing buildings. The Commercial Building Partnerships (CBP) is a public/private cost-share program addressing new and existing commercial buildings (DOE, 2011b). Replication of building measures utilized in the CBP program has significant market transformation potential for the commercial building sector in the U.S.

\subsection{The Commercial Building Partnership Program}

The CBP program was initiated in 2008 (CBP I), with a second funding opportunity presented in 2010 (CBP II) through the American Recovery and Reinvestment Act (ARRA). The selection process for these projects was competitive, with strict energy savings requirements mandated by DOE. Once selected, each partner committed to savings goals for new construction projects that were at least $50 \%$ greater than ANSI/ASHRAE/IESNA Standard 90.1-2004 or 2007. In existing buildings, retrofit projects were designed so that a building would consume at least 30\% less energy relative to either Standard 90.1-2004 or its historic consumption (DOE, 2011b).

The CBP program includes partnerships of commercial companies, with engineers and scientists from national laboratories and other energy efficiency experts designing, implementing and monitoring energy efficient measures for building construction and/or retrofits (usually one or two building projects per partner). National lab partners include the Lawrence Berkeley National Laboratory (LBNL), National Renewable Energy Laboratory (NREL), Argonne National Laboratory (ANL) and the Pacific Northwest 
National Laboratory (PNNL). EEMs include a broad array of technologies and applications to the building envelope, mechanical systems, electrical systems and approaches to operations and maintenance $(\mathrm{O \& M})$. The national laboratories provided modeling and design assistance to each partner. A package of EEMs was developed for each project based on business criteria provided by each partner.

To date, $\mathrm{CBP}$ has partnered with 42 entities on 54 specific new construction and retrofit projects, covering 8.3 million square feet of commercial building space (DOE 2011b). Total square footage of commercial building floor area included in partner portfolios amounts to about 4 billion square feet, approximately $6 \%$ of the total commercial building stock in the U.S. (DOE, 2011b; EIA, 2008). While the CBP program only addresses one or two buildings within an organization's entire building portfolio, replication of CBP program measures to all buildings within the portfolios could result in significant energy and cost savings.

This study presents findings from questionnaire and interview data investigating replication efforts of each CBP partner that worked directly with PNNL. PNNL partnered with 12 organizations on new and retrofit construction projects. Through a feedback questionnaire mechanism, along with personal interviews, PNNL gathered qualitative and quantitative data relating to replication efforts by each organization. This information was analyzed to provide insight into two primary research areas: 1) CBP partners' replication efforts of technologies and approaches used in the CBP project to the rest of the organization's building portfolio (including replication verification), and, 2) the market potential for technology diffusion into the total U.S. commercial building stock, as a direct result of the CBP program. 


\subsection{CBP Partner Replication Trends}

Research for the first part of this effort focused on replication efforts underway or planned by each CBP program participant. For this study, replication refers to implementation of technologies utilized in the CBP program, such as envelope, HVAC and lighting treatments, into other buildings owned by one particular organization. In addition, replication refers to the overall approach to green building and energy efficiency, which includes prototype development, operations and maintenance (O\&M), and measurement and verification $(\mathrm{M} \& \mathrm{~V})$ efforts. This study found that factors that impact replication include motivation, organizational structure and objectives firms have for implementing energy efficient technologies. Comparing these factors among different CBP partners may reveal patterns in motivation for constructing energy efficient buildings, along with greater insight into market trends for green building practices.

This chapter presents questionnaire and interview results from each CBP partner regarding replication efforts. The first section presents a discussion of the methodology, followed by an overview of CBP partner characteristics, and questionnaire and interview results.

\subsection{Methodology}

The research team gathered information from each CBP I and CBP II partner through a feedback questionnaire mechanism, followed by a telephone interview. Both the questionnaire and follow-up interviews were completed by the CBP partner's overseeing project manager, who was often the director of facilities, managing director of construction, or director of energy and engineering. The feedback questionnaire was designed to obtain information for analysis of replication within the CBP program. Specifically, the questionnaire and interviews explored how measures, treatments and processes adopted in the design process for specific retrofit or new construction projects are being replicated throughout the entire portfolio of the CBP participant.

The focus of this study addresses two primary research questions:

1. How are CBP partners replicating specific measures, treatments and processes throughout their building portfolios? How are these efforts verified?

2. How are efforts undertaken through the CBP program diffusing into the overall commercial building sector?

Protocol development for this study aimed to ensure that data gathered from each participant was collected using a systematic approach and set of questions, providing both quantitative (questionnaire) and qualitative (interview) data. There were two formats of questions:

1. A feedback questionnaire mechanism, distributed through SurveyMonkey, with scaled, yes/no, multiple choice, multi-select, and open-ended questions. The feedback questionnaire was completed by CBP partners in May 2013.

2. A personal telephone interview with follow-up questions, open-ended in nature, designed to give further insight into replication efforts. Follow-up interviews with CBP partners were completed in June 2013.

The feedback questionnaire mechanism was distributed before the interviews were conducted and included three primary sections. The first section was designed to inform PNNL about CBP partner structure, motivations and objectives for implementing CBP measures; the second section was designed 
to inform PNNL about specific replication strategies and outcomes of replicating CBP measures; and the third section was designed to inform PNNL about the outcomes of replication, documentation processes and long-term monitoring of CBP measures. Questionnaire data was analyzed using basic descriptive statistical methods in order to better understand the replication efforts by partners.

Once the questionnaires were complete, PNNL staff conducted a telephone interview with the managing engineer or other representative from each partner organization. Each interview lasted between 15 and 45 minutes, depending on the time availability of each interview participant. In general, the telephone interview was used to gain further understanding, clarification and detail about the questionnaire answers, particularly the open-ended questionnaire questions. The interview format followed the same three categories as the online questionnaire, with particular focus on gaining an in-depth understanding about the partner's experience before, during, and after completion of the CBP program.

The questionnaire and interview outcomes were integrated and are presented in the sections below. The first section discusses the basic characteristics of the sample studied for this effort; the second section discusses program participation details; the third section presents specific replication trends; and the fourth section provides information about quality assurance, replication protocol development and objectives.

\subsection{Overview of CBP Participant Characteristics}

The questionnaire response was a total of 9 CBP partners, representing 11 projects, from a total of 10 possible respondents (12 projects) overseen directly by PNNL. While the total response number is low, it represents $28 \%$ of all organizations participating in the CBP program, and over 1.4 million square feet of commercial building space. Total square footage of the building portfolios for these 11 partners is close to 1.9 billion square feet of commercial building space. Figure 2 below presents CBP partner profiles by industry, for the group analyzed in this study. There was an even split between education, finance \& financial services, government, and retail (22\%). The commercial real estate industry was also represented at $11 \%$. 


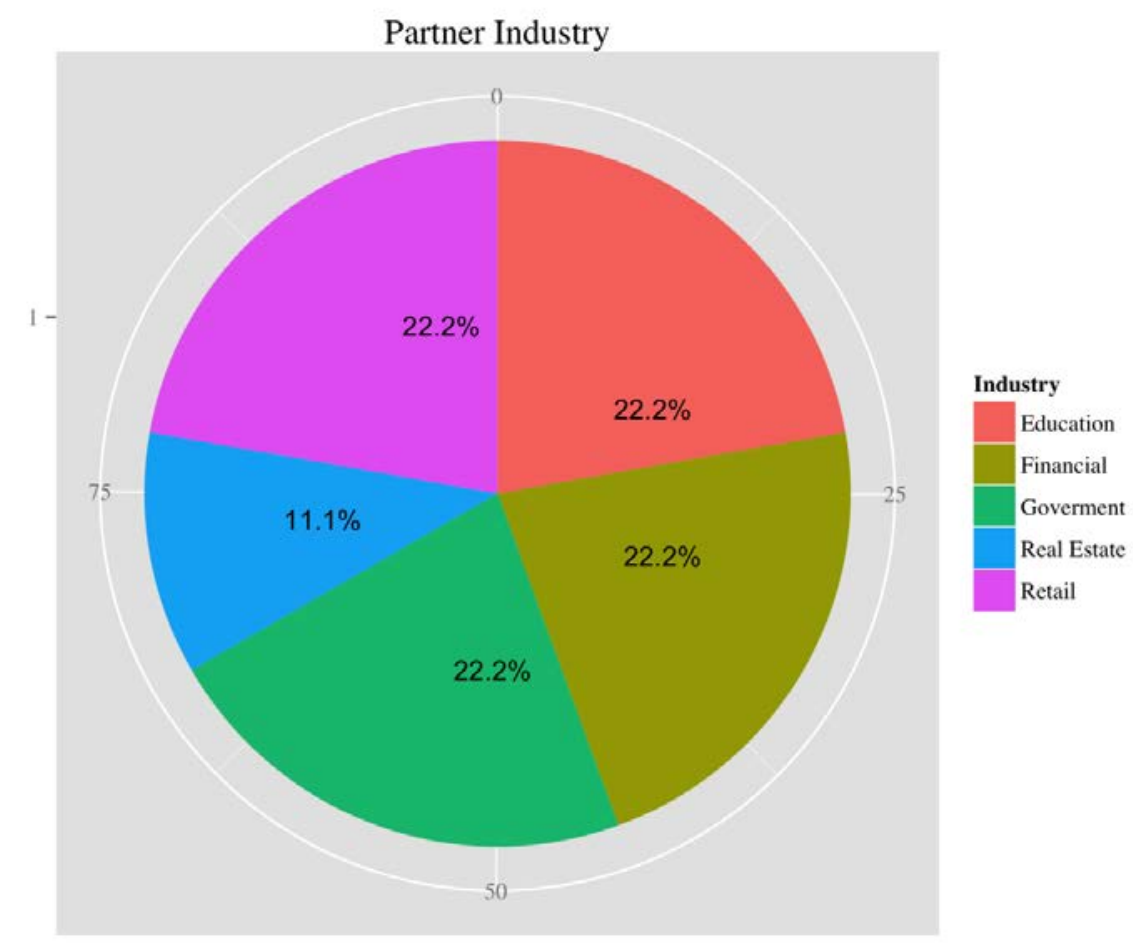

Figure 2. CBP Partner Participation by Industry as Reported by Questionnaire Respondents (N=9)

Most CBP partners participated in other green building programs before, during or after the CBP program. Of all questionnaire respondents, $89 \%$ indicated participation in the green building initiatives shown in Figure 3. All CBP partners (100\%) who participated in other green building programs were involved in the U.S. Green Building Council's (USGBC) Leadership in Energy and Environmental Design (LEED) program. In addition to LEED, 63\% participated in the ENERGY STAR program, 25\% in the Better Buildings program and $50 \%$ in regional utility programs for commercial buildings. Three respondents indicated that achieving LEED certification is part of their building protocol.

Follow-up interviews conducted for this effort revealed that some of the particular EEMs applied to new and retrofit construction through the CBP program were also utilized by other programs, such as LEED. Because many partners had already been involved in other green building programs utilizing these EEMs, they did not consider transferring these technologies into other buildings as "replication." This fact leads to a lower replication response rate of $43 \%$ discussed in the replication section below. Three respondents indicated they received utility subsidies for portions of their projects. 


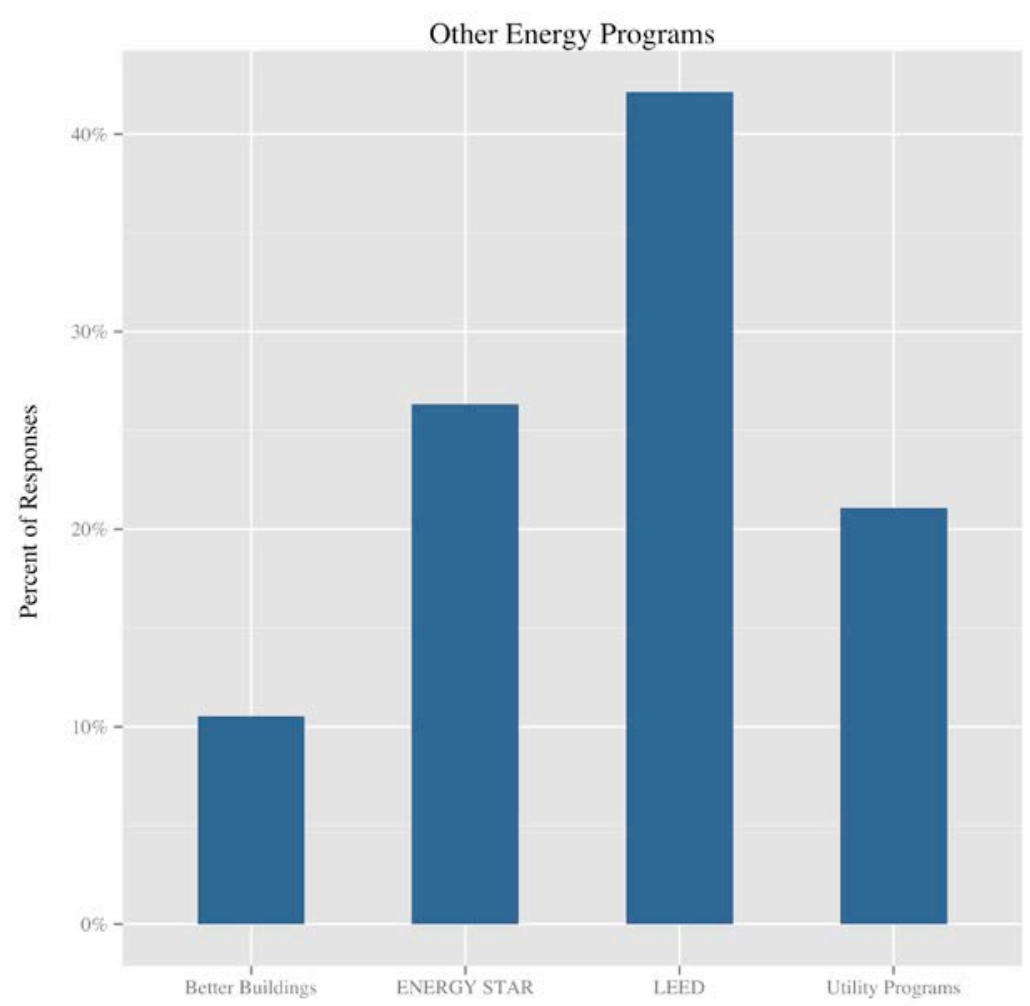

Figure 3. CBP Partner Program Participation Before, During or After their CBP Building Project, by Percentage of Questionnaire Participation (Multiple Responses Allowed)

As shown in Figure 4 below, the majority (56\%) of projects were related to new construction. Retrofit construction totaled $11 \%$, and three partners worked on multiple projects consisting of new and retrofit project simultaneously. Several of the CBP partners had multiple buildings in the program that one new construction and one existing building project. 


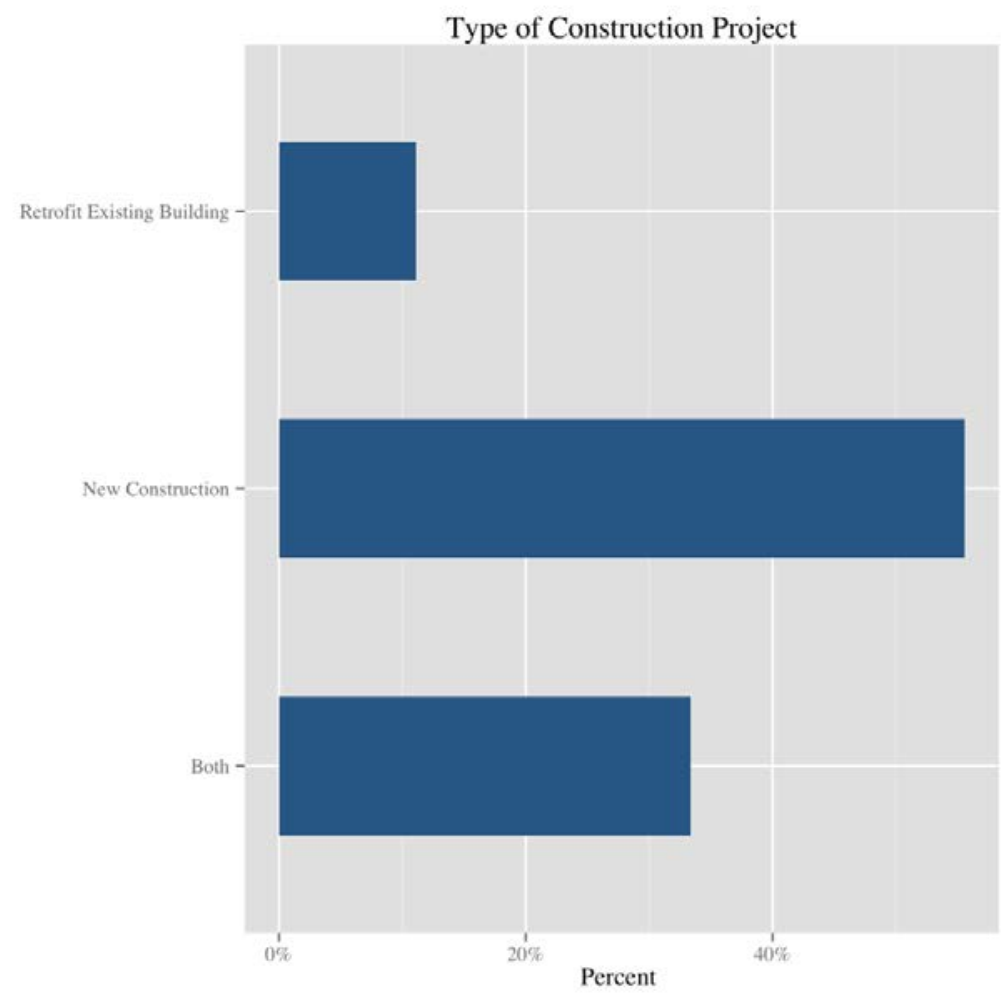

Figure 4. Percentage of CBP Projects by Building Type (N=9)

The majority of CBP partners that participated in this study have finished construction and occupied their new or existing building project (67\%). Figure 5 below presents the design phase of all partners that participated in this study, as of June 2013. 


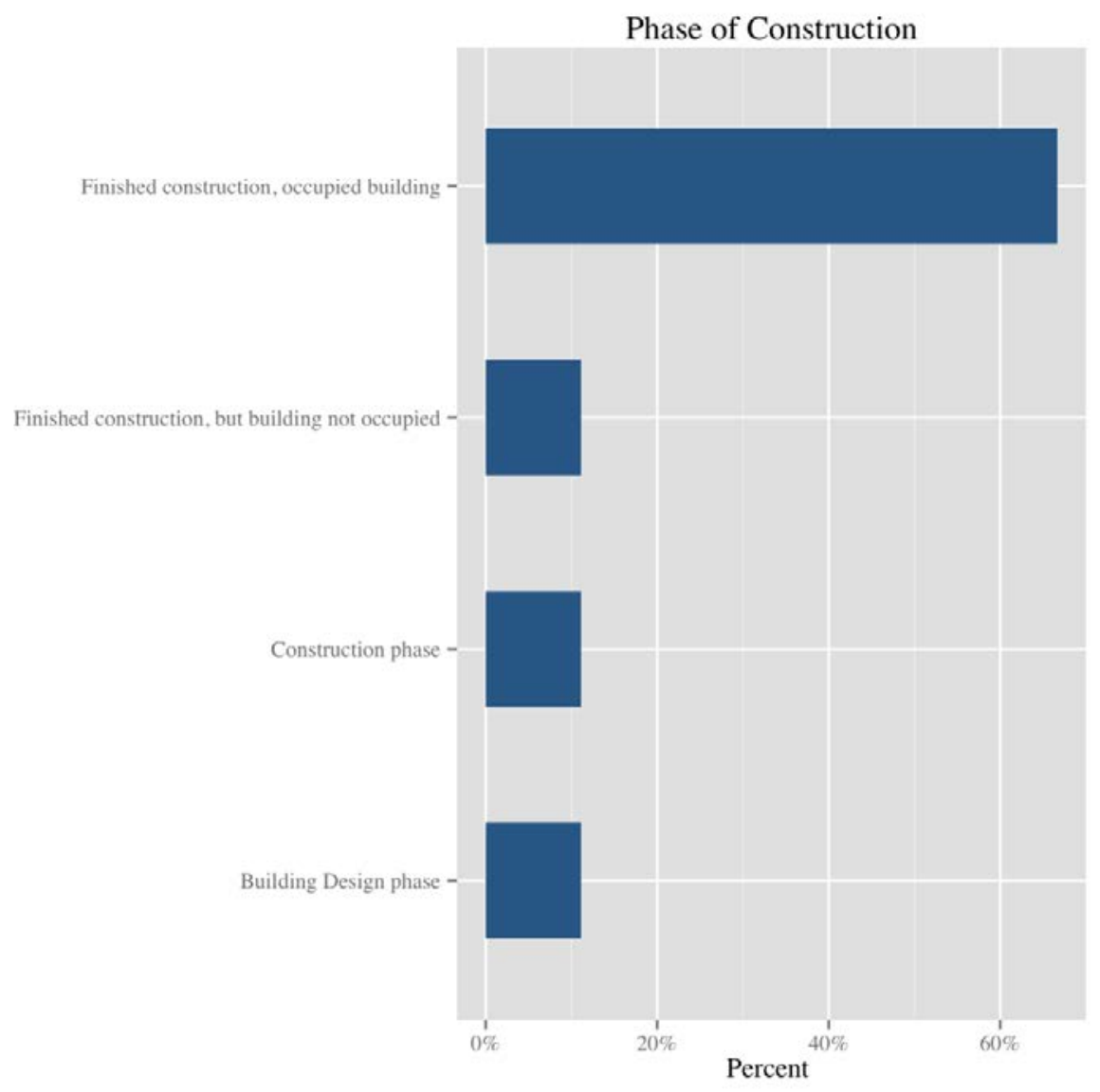

Figure 5. Current Phase of Construction for Each CBP Partner

\subsection{CBP Program Participation Details}

This section discusses questionnaire and interview data relating to construction details, energy and cost savings, and investments in green building strategies.

The partners were asked to forecast energy savings over the next 5 to 10 years for their building project. As shown in Figure 6, most partners expect to see whole building energy savings in the range of 31 to $50 \%$ compared to existing prototypes for construction (new and existing buildings). A few partners did not respond to the question as shown the left-most bar in the figure. A few partners expect to see energy savings higher than $50 \%{ }^{1}$

\footnotetext{
${ }^{1}$ For this analysis, energy savings is defined as site energy use.
} 


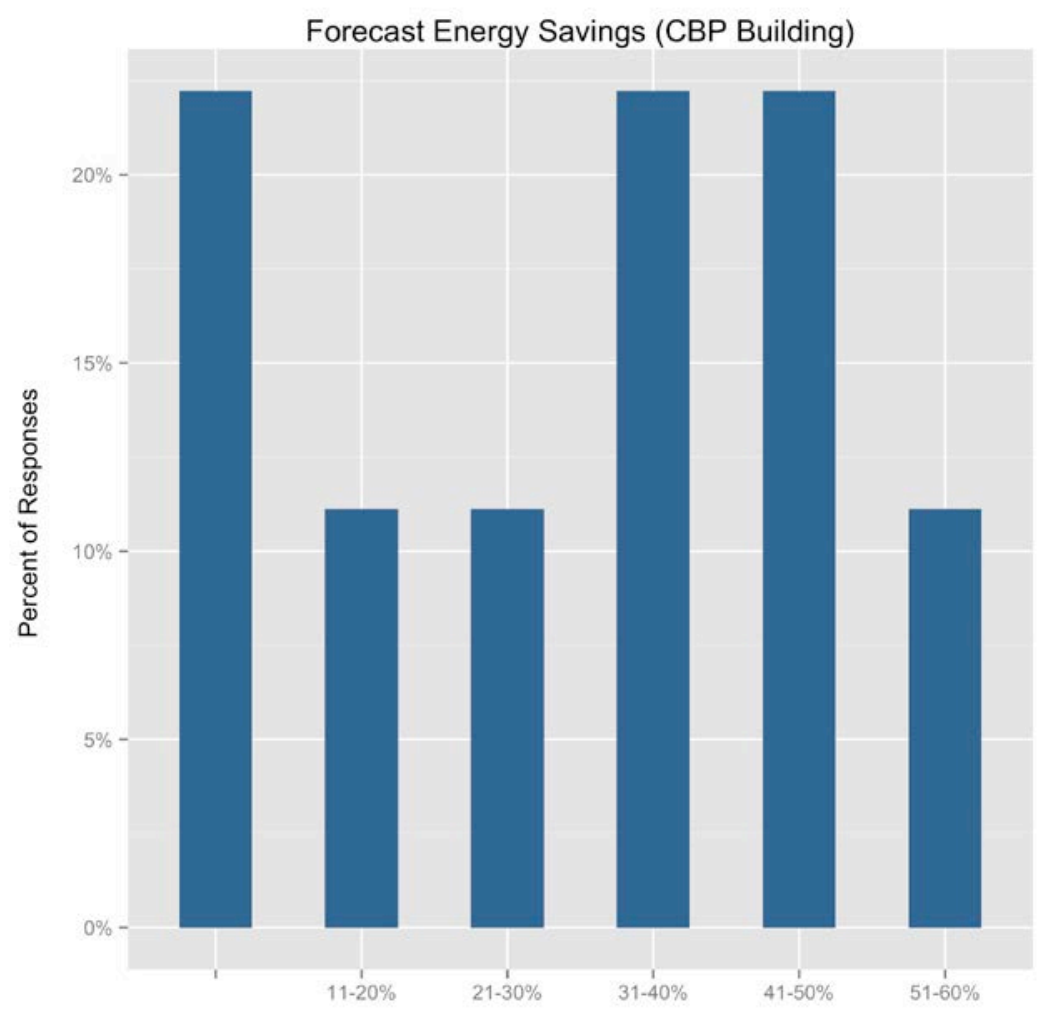

Figure 6. CBP Partner Forecast Energy Savings for the CBP Building in the Next 5-10 Years as Reported in the Questionnaire.

The partners were also asked to predict cost savings of energy expenditures for the CBP building as shown below in Figure 7. To better understand the way the partner expects the CBP methods to propagate through the full building portfolio, the partners were also asked to estimate the cost savings expected for the full portfolio. As shown in Figure 8 the majority of respondents indicated 5-10\% cost savings in the full building portfolio. While these savings are relatively modest compared to energy savings, multiple partners indicated that energy expenditures represent one of the largest percentages of total operational costs, and that 5-10\% savings represents significant $\mathrm{kWh}$ and dollar amounts. 


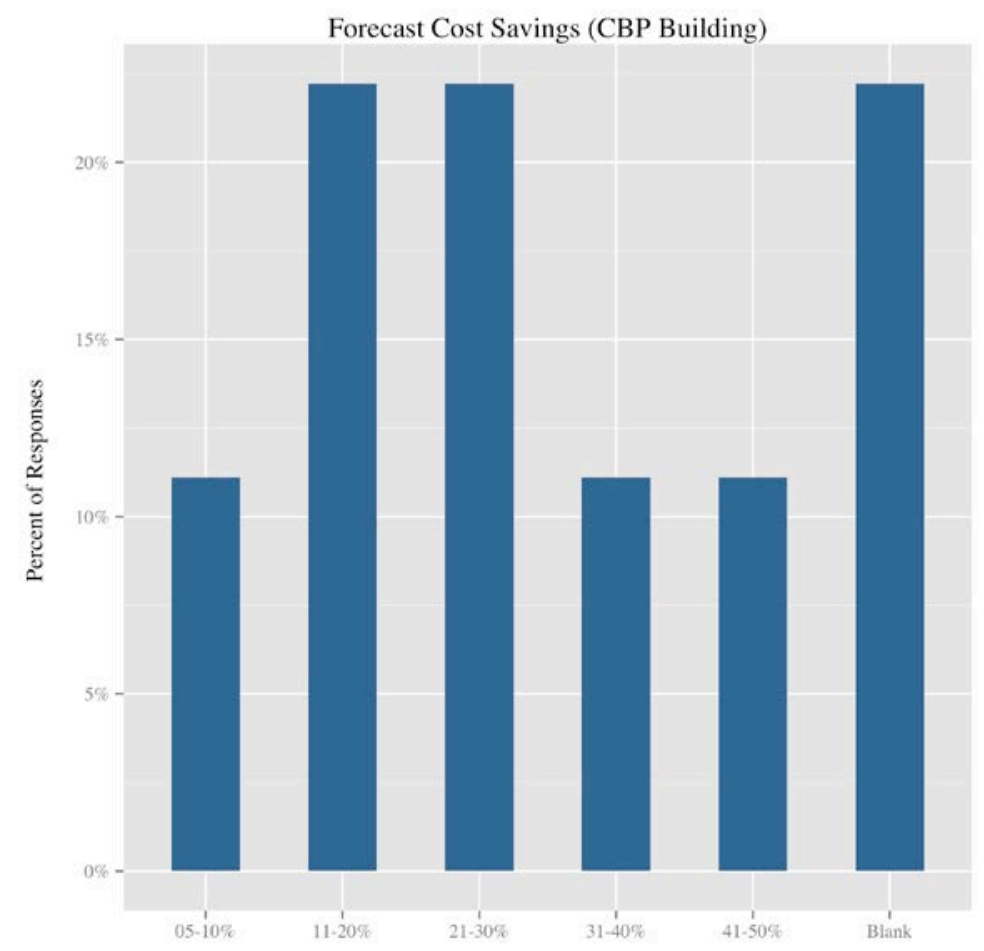

Figure 7. CBP Partner Forecast Cost Savings for the CBP Building in the Next 5-10 Years as Reported in the Questionnaire.

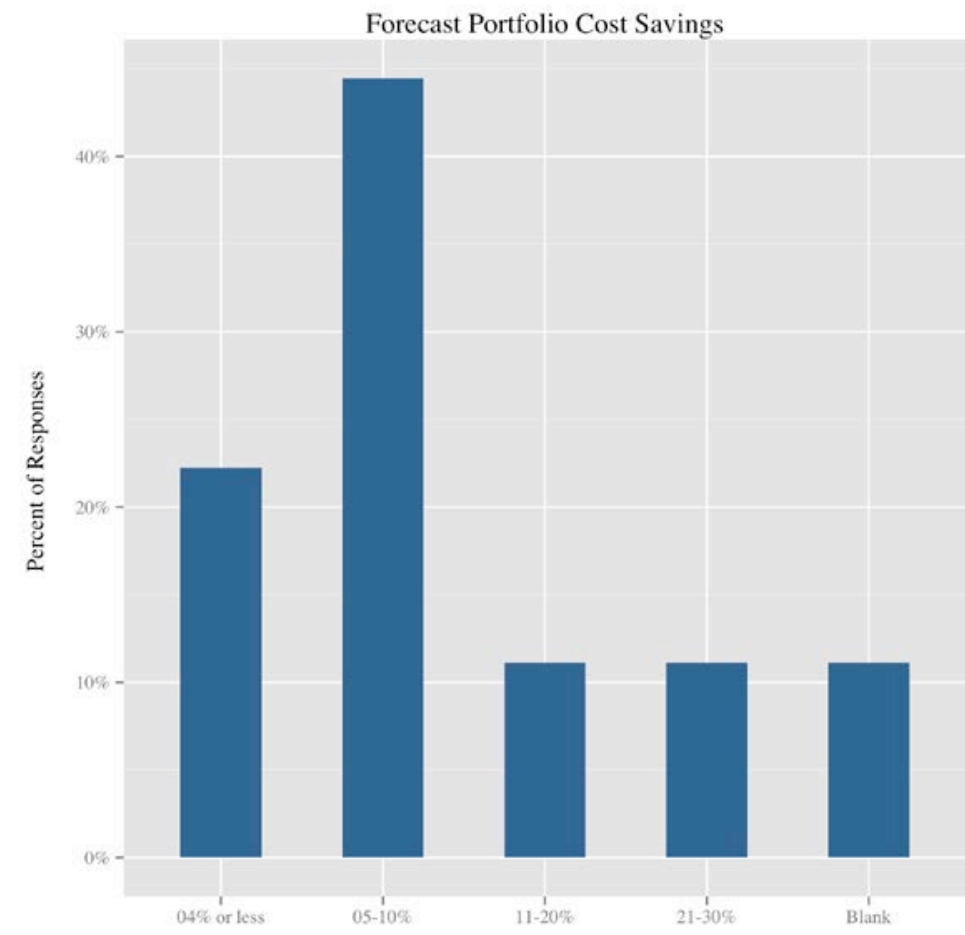

Figure 8. CBP Partner Forecast Energy Savings for the Partner Portfolio in the Next 5-10 Years as Reported in the Questionnaire. 
Partners were asked how they monitored their project during the process of construction. Eight respondents indicated their building projects were commissioned, and monitoring of their project included commissioning agents. As the majority of organizations that participated in the CBP program are large corporations, most respondents indicated the monitoring process was conducted by an in-house team of engineers and project managers who conducted site visits during all steps of the construction process.

When CBP partners were asked about how they prioritize investments in energy efficiency, respondents all indicated that investments in energy efficiency provided substantial operational cost savings. One respondent indicated that a simple payback of 7 years or less was the primary determinant when analyzing EEMs. Four respondents disclosed that energy efficiency investments are highly prioritized by the organization due to voluntary sustainability mandates that include energy reliability.

\subsection{CBP Partner Replication Trends}

Both the questionnaire and interview process yielded data regarding specific replication efforts of a variety of EEMs and reasons for replicating these technologies into other buildings within their portfolios. Most participants indicated their specific CBP efforts will act as a testbed for upcoming new construction or retrofit projects. Multiple interviewees pointed out that their building projects provided valuable lessons that could be applied to other future construction projects, allowing the organizations an opportunity to optimize energy efficiency benefits specific to their energy consumption patterns and needs. This differs from other green building programs, which require a checklist-type system of prescriptive or benchmark requirements.

The questionnaire respondents were split when specifically asked if they would install measures from the CBP project into the rest of the partner building portfolio. $43 \%$ indicated they would and $57 \%$ indicated they were unsure. None of the respondents indicated they would not replicate measures throughout the portfolio. The split in this response may indicate that many of the questionnaire respondents (57\%) are unsure of replication through the entire portfolio, but they may be replicating specific measures through part of the portfolio. Follow-up interviews with partners revealed that some EEMs, such as high efficiency HVAC systems and high roof/ceiling insulation, are measures the organization was using prior to participation in the CBP program. Partners indicated that they did not consider implementation of such measures as "replication." When asked whether replication efforts were a direct result of participation in the CBP program, three respondents indicated yes. A number of partners have identified measures that will be replicated across many buildings or their entire portfolios. Discussion of specific EEM replication efforts are discussed in the next section of this report.

The partners were also asked in how many other buildings in which CBP measures had already implemented. Even a few years into the project significant replication is occurring and some respondents indicated replication as high as 6 or 10 buildings. However, most of the partners have not yet replicated the CBP methods beyond the one or two buildings as shown in Figure 9. Still, the majority of partners are replicating measures as a direct result of their participation in the CBP program; 63\% said they did not have replication protocols before participating but now do. 


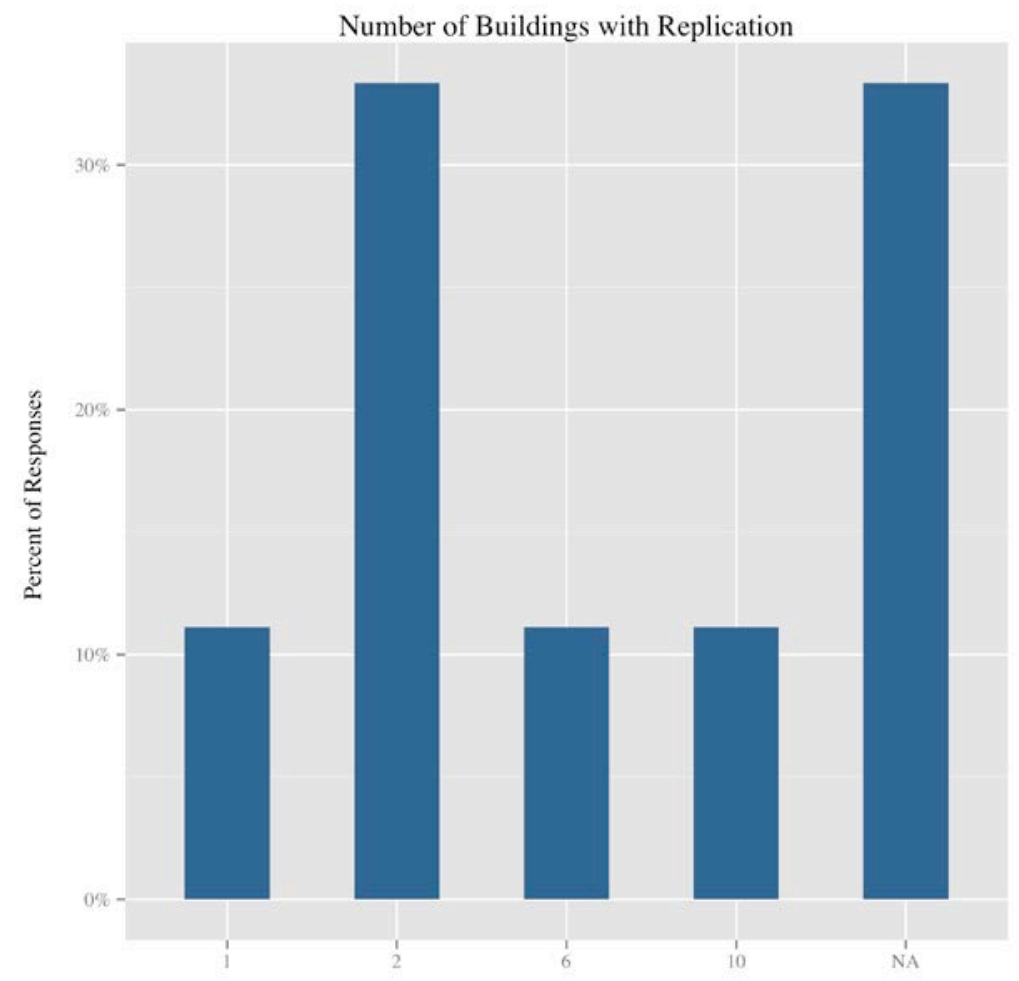

Figure 9. CBP Partner Reported Number of Buildings with Replication at the Time of the Questionnaire.

In addition to general program replication, partners were asked to identify specific EEMs (listed in Table 1) applied to their building project(s), which included a variety of HVAC, lighting, envelope, renewables, design and water systems. The technologies in Table 1 are consistent with the State of California's Real Estate Services Division Energy Efficiency and Sustainable Building Measures Checklists (State of California, 2002). Table 1 below presents a list of these technologies and the rate of replication for each one by CBP partners:

Table 1. Technologies Replicated from the CBP Program

\begin{tabular}{|l|c|}
\hline Energy Efficient Measures (EEMs) & $\begin{array}{c}\text { Respondent } \\
\text { Replication } \\
\text { (\%) }\end{array}$ \\
\hline Lighting - low wattage exit signs & $100 \%$ \\
\hline Point Use Controls - occupancy sensors & $100 \%$ \\
\hline Energy Management System - programming, commissioning and optimization & $100 \%$ \\
\hline Lighting - light colored interior finishes & $86 \%$ \\
\hline Water - ultra low flush toilets & $86 \%$ \\
\hline Water - low-flow faucets \& showerheads & $86 \%$ \\
\hline ENERGY STAR equipment (computers, TVs, video, etc.) & $86 \%$ \\
\hline ENERGY STAR appliances (refrigerators, washing machines, etc.) & $86 \%$ \\
\hline HVAC - high efficiency motors & $71 \%$ \\
\hline HVAC - high efficiency chillers & $71 \%$ \\
\hline Lighting - LED & $71 \%$ \\
\hline
\end{tabular}




\begin{tabular}{|l|l|}
\hline Point Use Controls - carbon dioxide monitors & $71 \%$ \\
\hline Energy Management System - real-time energy metering & $71 \%$ \\
\hline Envelope - high-R roof/ceiling insulation & $71 \%$ \\
\hline HVAC - high efficiency boilers/furnaces & $57 \%$ \\
\hline HVAC - heat recovery & $57 \%$ \\
\hline HVAC- carbon monoxide controls & $57 \%$ \\
\hline Lighting - low power density & $57 \%$ \\
\hline Lighting - exterior lighting (parking lots, etc.) & $57 \%$ \\
\hline Point Use Controls - programmable thermostats & $57 \%$ \\
\hline Envelope - cool roof system & $57 \%$ \\
\hline Water - insulated pipes between supply and faucets & $57 \%$ \\
\hline HVAC - high efficiency cooling towers & $43 \%$ \\
\hline HVAC - variable-flow chillers & $43 \%$ \\
\hline HVAC - demand control variable exhaust & $43 \%$ \\
\hline Lighting - indirect lighting options & $43 \%$ \\
\hline Daylighting - shading systems & $43 \%$ \\
\hline Envelope - high-R windows & $43 \%$ \\
\hline Envelope - high-R wall insulation & $43 \%$ \\
\hline Energy Sources/Renewables - photovoltaic & $43 \%$ \\
\hline Water - exterior management (bioswales, etc.) & $43 \%$ \\
\hline Lighting - minimum CFL efficacy 50 lumens/watt & $29 \%$ \\
\hline Daylighting - skylights/solar tubes & $29 \%$ \\
\hline Envelope - high-R floor/foundation insulation & $29 \%$ \\
\hline HVAC - GSHP and/or geothermal heat pumps & $14 \%$ \\
\hline Load Shifting/Shedding - cycling, remote metering and controls & $14 \%$ \\
\hline Load Shifting/Shedding - on-demand water heaters & $14 \%$ \\
\hline Energy Sources/Renewables - solar thermal & $14 \%$ \\
\hline HVAC - boiler nitrous oxide emissions control & $0 \%$ \\
\hline HVAC - avoid direct evaporative cooling & $0 \%$ \\
\hline HVAC - evaporative pre-cooled condensers on rooftop units & $0 \%$ \\
\hline Lighting - minimum linear fluorescent efficacy 76 lumens/watt & $0 \%$ \\
\hline Point Use Controls - 365 digital clocks & $0 \%$ \\
\hline Energy Sources/Renewables - cogeneration plant & $0 \%$ \\
\hline Energy Sources/Renewables - onsite wind system & $0 \%$ \\
\hline & \\
\hline & \\
\hline & \\
\hline
\end{tabular}

Of all the specific technologies represented in Table 1 above, three have a 100\% replication rate:

- Lighting - low wattage exit signs

- Point Use Controls - occupancy sensors

- Energy Management System - programming, commissioning and optimization

Similar to Table 1, Figure 10 below identifies EEMs by primary category, and is broken out to show the penetration rates by building sector. Figure 10 illustrates that the HVAC and lighting measures were the most popular measures for replication for all building sectors, even though some partners did not consider HVAC EEMs to be replicable because they were already doing it. Follow-up interviews revealed that many partners found LED technologies to be very promising for future energy and cost reductions. One partner in particular noted that the approach to LED installation led to savings they had not anticipated before participation in the CBP program. 


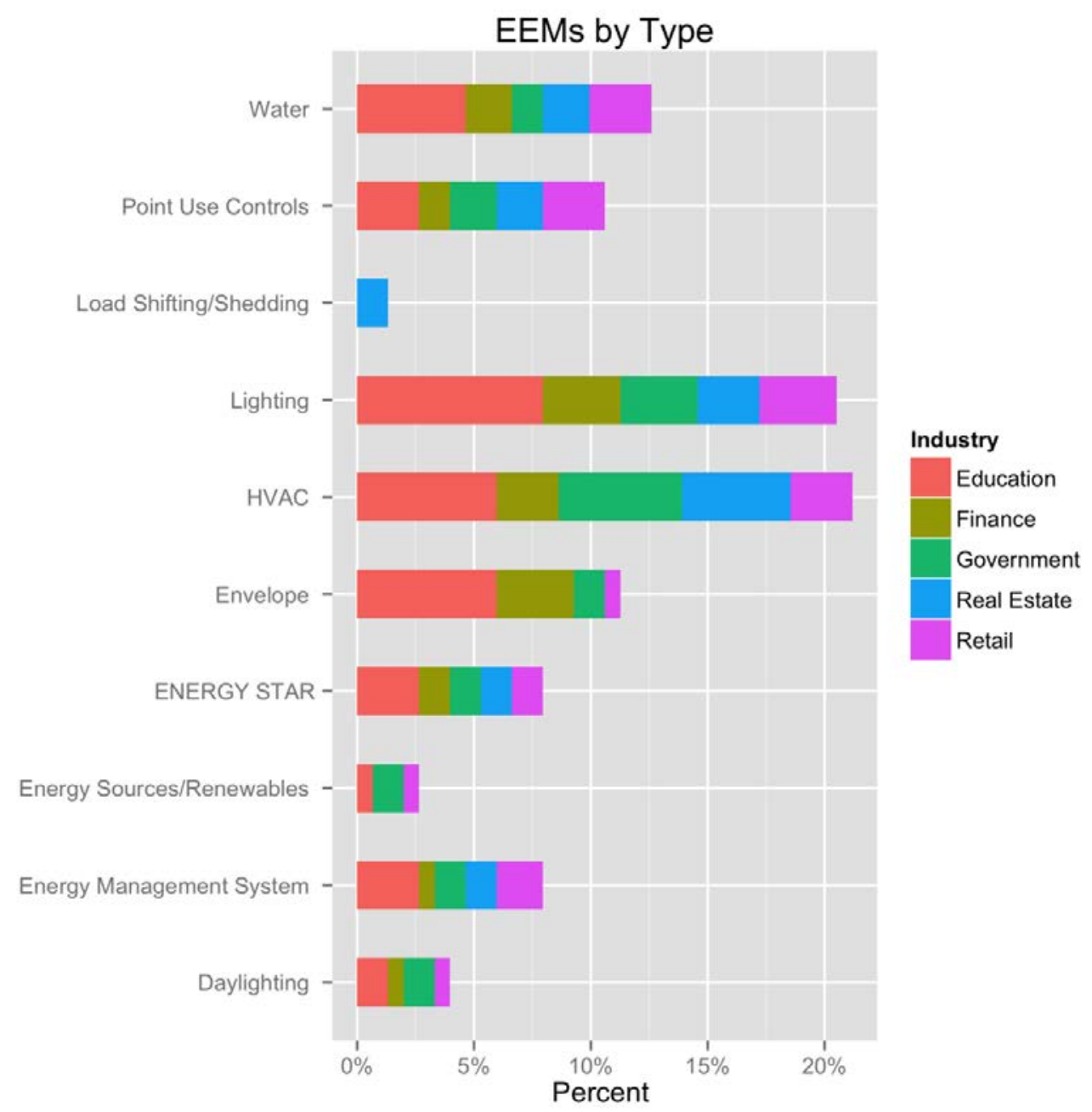

Figure 10. CBP Partner Reported EEMs by Type and Building Sector

In addition to the table above, one partner indicated that they are installing variable frequency drives (VFD) on rooftop HVAC units in 130 stores. Two respondents indicated that VFDs represented the greatest energy savings when installed on chillers and HVAC fan motors, compared to other EEMs. One respondent indicated that VFDs represented the greatest cost savings compared to other EEMs installed during the program. Of questionnaire respondents, the educational sector had the broadest adoption of EEM categories.

In the interviews conducted after the questionnaires were completed, the following takeaways were identified by CBP partners regarding specific measures or implementation strategies they will now replicate based on their experience with the CBP program:

- Two partners indicated that they now have a detailed plan for $M \& V$ programs that will be rolled out to all building engineers within the organization.

- One partner indicated significant savings potential from reducing plug loads, an area that was not focused on before participation in the CBP program. 
- One partner indicated that the entire package of CBP EEMs will be replicated in all buildings owned by the organization.

- Three partners indicated that LEED standards are mandated in all new construction. Specific elements from the experience gained from the CBP program will be added to their existing energy efficiency protocols.

- Three partners indicated that enhanced weather modeling and EEM package optimization were primary takeaways from program participation.

- Six partners confirmed that LED lighting technology and design will now be used in their entire building portfolios thanks to participation in the CBP program.

- One partner learned they were oversizing HVAC equipment and intends to use right-sized equipment in all new construction and replacements in their portfolio.

The primary motivation for CBP program participation, indicated in both questionnaire and interview results, was cost reduction. In addition to realizing increased efficiency, installation of energy efficient technologies has been determined by many researchers to provide economic benefits. Overall building design can help achieve energy and cost savings. For example, design solutions to existing commercial buildings based on the climate zone in which the building is located has been estimated to have a cost savings potential of 10 to $20 \%$ (Belzer, 2009), relatively consistent with the 11-30\% reported by CBP partners. Other studies point to economic gains from lower operational costs of HVAC systems due to increased envelope efficiencies (Kneifel, 2010; Howarth, 2010).

Replication efforts by CBP partners depend greatly on potential cost savings and project economics. When asked about economic analysis metrics, half of the respondents indicated that return on investment (ROI) was their primary economic criterion. Figure 11 illustrates the primary types of economic analyses used to evaluate the investment potential for replicating CBP measures. These measures include simple payback, savings to investment ratio (SIR), return on investment (ROI), life-cycle cost analysis (LCC) and building life-cycle cost analysis (BLCC). BLCC methods allow analysis of capital investments specific to buildings. Most respondents use a form of spreadsheet or commercial software to calculate EEM investment opportunities. Two respondents indicated they do not utilize any financial analysis software, while the rest of the respondents maintained they utilized in-house financial tools or packaged software suites to evaluate the economics of EEMs. 


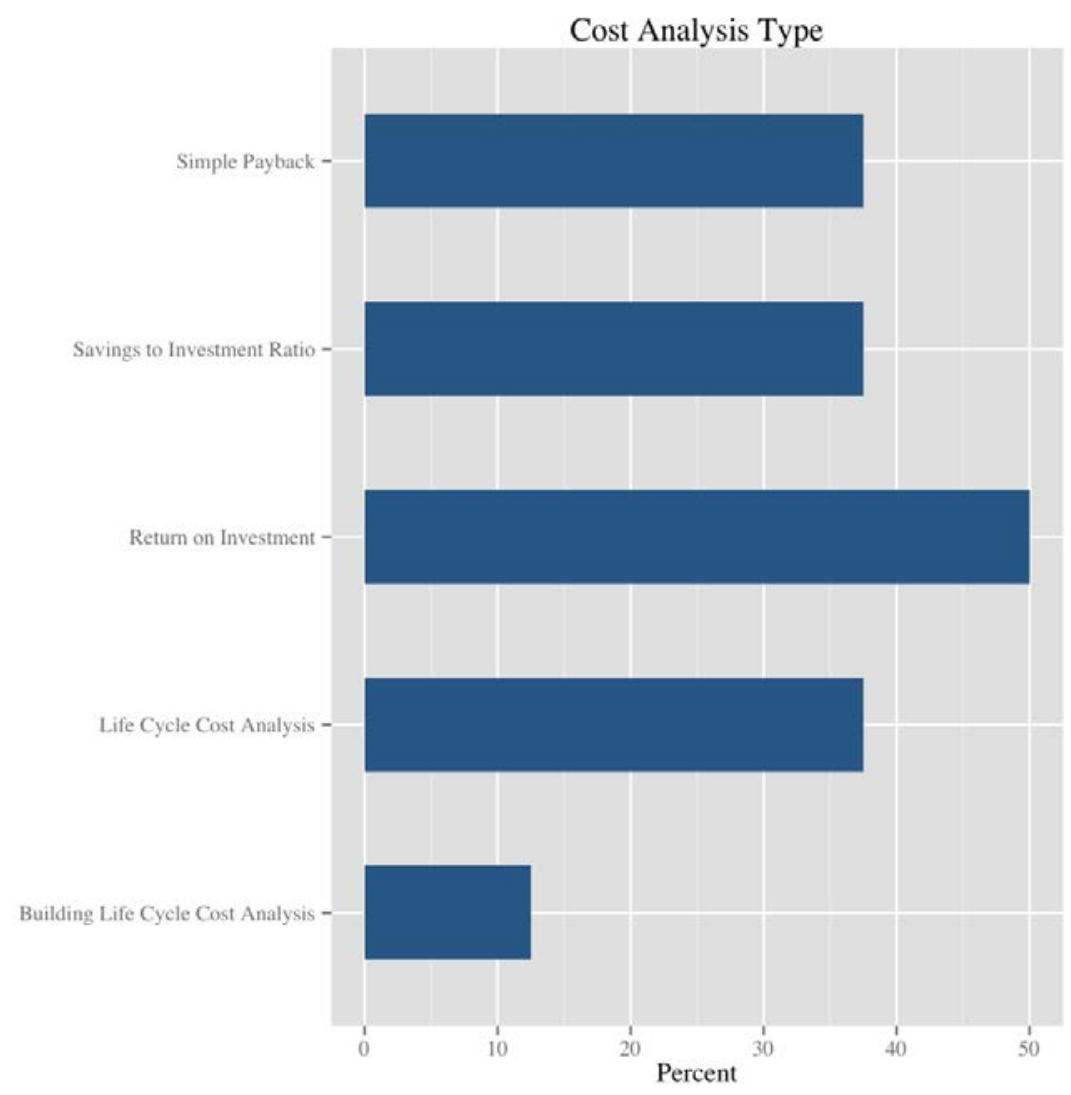

Figure 11. Economic Metrics used by CBP Partners to Measure EEM Cost Effectiveness

Follow-up interviews conducted for this effort indicated the following takeaways from the CBP program regarding cost reduction:

- All participants except one were strongly motivated by cost reduction potential;

- Five CBP partners indicated that energy costs are amongst the largest cost categories in expense budgets;

- Three participants indicated that energy modeling and monitoring techniques will be utilized henceforth to better understand the energy profile of specific buildings within the organization's portfolio. They believe that this enhanced knowledge will help them reduce energy related costs.

\subsection{Motivation and Evidence of Replication}

Whether an organization decides to replicate EEMs, originally installed during their participation process of the CBP program depends on economics of the project (as discussed previously), and organizational structure or behavior. A growing literature is focusing on the behavioral sciences to investigate nonmonetary motivations for increased energy efficiency (Allcot and Mullainathan, 2010). This section explores behavioral motivations for replication by CBP partners, and evidence of replication endeavors or plans. In an effort to measure and provide evidence of replication, PNNL designed a portion of the questionnaire and interview to better understand documentation, project planning, and $\mathrm{M} \& \mathrm{~V}$ of $\mathrm{CBP}$ projects. 
One motivating factor besides cost and energy reduction, impacting the willingness of companies to engage in increased energy efficiency or other sustainable building programs is overall organization culture. Organizations that encourage corporate social responsibility (CSR) programs or are environmentally minded tend to be more willing to invest in technologies or applications that improve building or operational efficiency (Kahanna et al., 2007). In terms of CBP partners, all participants interviewed for this study indicated that CSR, company culture and sustainability initiatives played a part in the organization's willingness to participate in the CBP program and invest the upfront capital necessary for efficiency upgrades in new or existing building. One respondent identified that the CBP program was an opportunity to increase education, awareness and competency for sustainable operations.

Respondents were asked whether they have organization-wide sustainability protocols for green building, energy efficiency and environmental stewardship. All of the respondents indicated their organization had policies and procedures regarding sustainability. Additionally, $75 \%$ of questionnaire respondents indicated that they have company policies regarding implementation of EEMs (Figure 12). When asked whether these protocols impacted their participation in the CBP program, $75 \%$ of respondents indicated yes, while $25 \%$ indicated no.

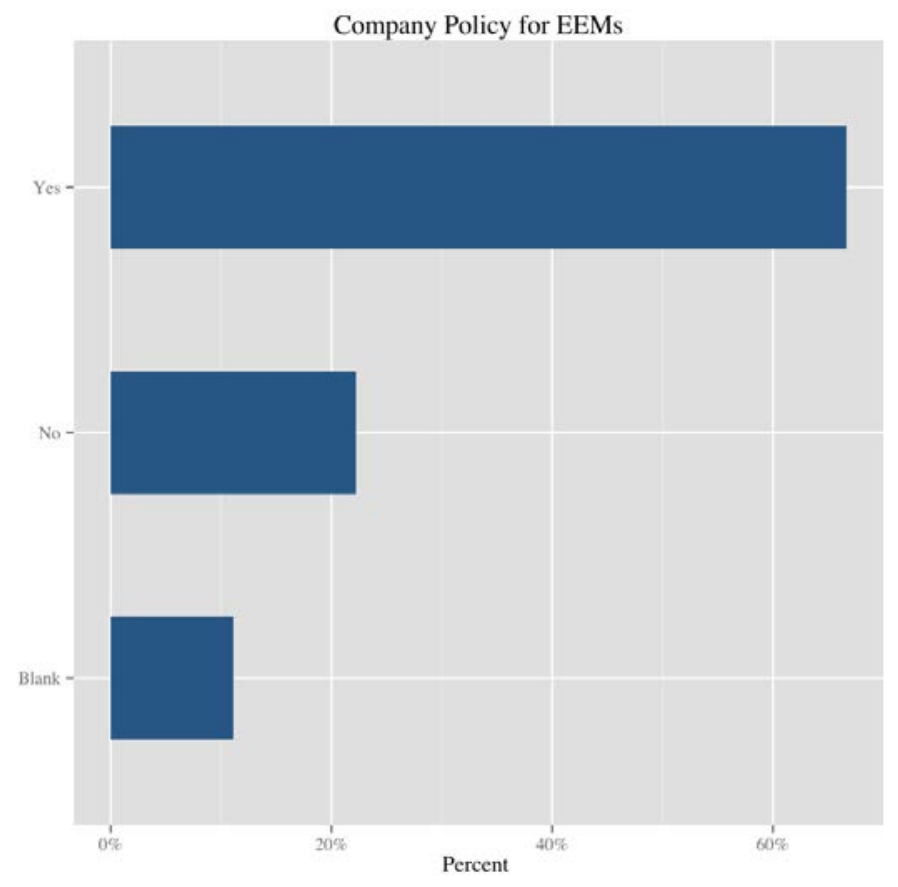

Figure 12. Percentage of Organizations with Policies/Procedures for EEM Implementation

PNNL also aimed to gain a better understanding of any benefits beyond the energy and cost savings CBP partners realized through program participation. Respondents were asked to rank ten different nonmonetary and social benefits associated with increased building efficiency. Figure 13 presents the cumulative results from all respondents; the $\mathrm{x}$ - axis represents the number rank per respondent and the $\mathrm{y}$ axis represents the benefit. Decreased maintenance was ranked highly by more than $50 \%$ of the questionnaire respondents. This is consistent with the reduced cost of exterior lighting that many partners reported when switching to LED systems. Increased employee productivity and comfort were also ranked highly by the partners. Positive media and marketing opportunities were also a factor for some partners, but typically ranked lower. 


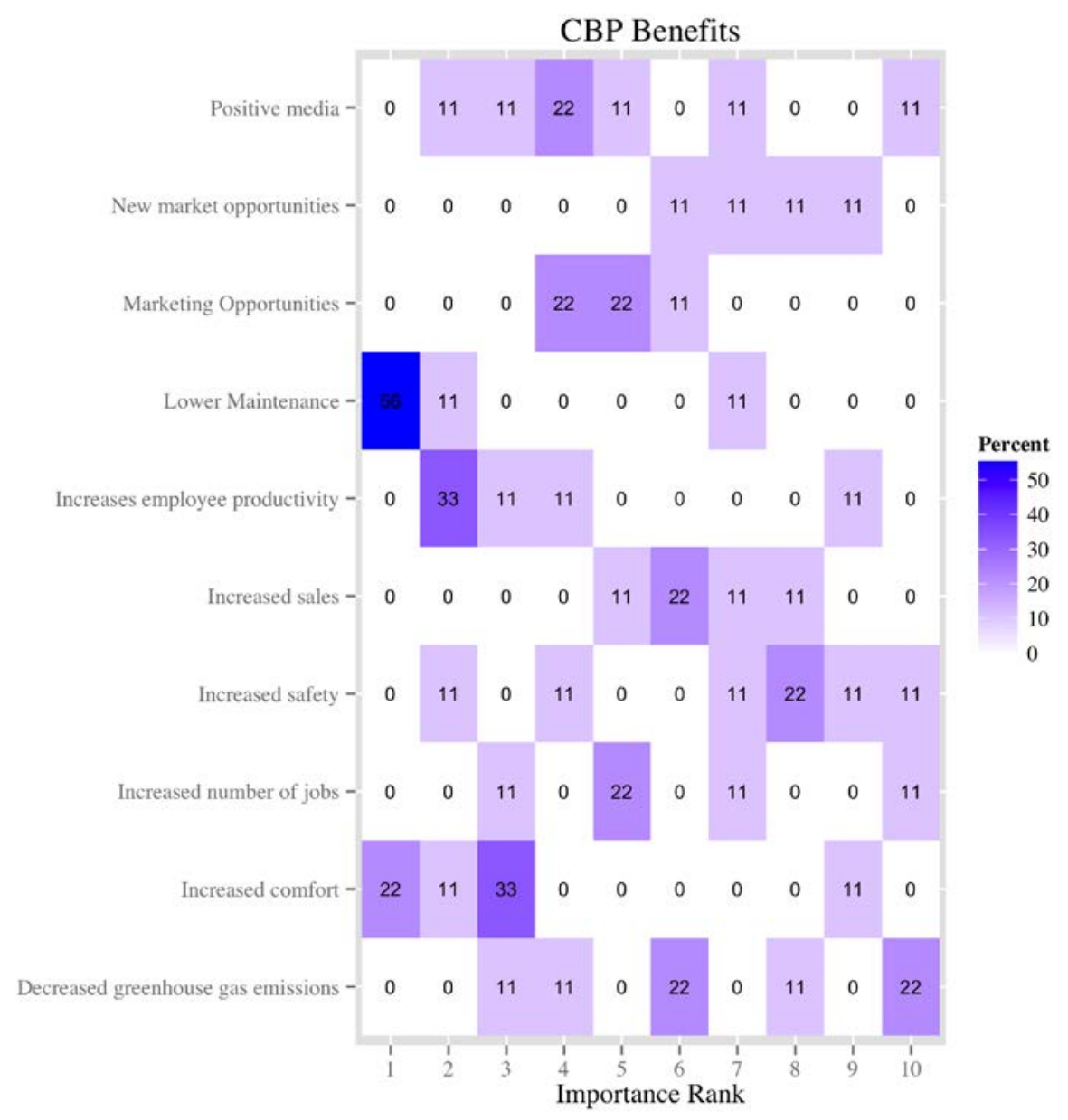

Figure 13. Questionnaire Responses to CBP Benefits beyond Energy and Cost Savings. Respondents Ranked the Benefits and Percentage of Responses are Shaded.

One way to determine replication impacts over the long term is to gain insight into protocol development, monitoring and verification activities, and operations plans and documentation of CBP partners. Better understanding of these organizational structures can help provide validation and demonstration that replication is occurring, and that it is successful and impactful when compared to the overall energy footprint of an entire organization.

Building commissioning is a term used to describe a comprehensive project management process for new and retrofit (retro-commissioning) construction that provides an in-depth quality assurance process from the design through the occupancy phase of the building project (ASHRAE, 2011). Successful building commissioning can reduce energy costs and enhance systems operation of building projects. In an effort to better understand long-term replication objectives, CBP partners were asked whether their building projects were commissioned (or retro-commissioned). As noted previously, 88\% responded yes. When asked whether all buildings are commissioned, 75\% replied yes, $12.5 \%$ no, and $12.5 \%$ "I don't know."

Respondents were also asked whether they have a documentation process for building design and energy efficiency. Of the seven participants that responded to the question, four indicated they did, and three 
indicated their organization did not. One of the organizations that answered no to that question is a franchised property management company, which is not involved in all their franchise's building projects.

When asked about protocols for $\mathrm{M} \& \mathrm{~V}$, all but one respondent indicated they had some form of $\mathrm{M} \& \mathrm{~V}$ process, which included metering. However, three respondents reported they did not have a process for monitoring before the CBP program. Two respondents did not answer the question. Respondents that answered "yes" indicated either in-house, third party or no M\&V. All CBP projects are monitored by the DOE design team for a specified period of time; this question was designed to gain insight into how the organization plans for long-term building monitoring.

When asked about prototype plans, four partners indicated they develop and maintain building construction prototypes. Three respondents keep the prototype plans in-house, and one is maintained by a third party engineering firm, hired by the organization to maintain their energy profile. In a follow-up interview, one partner reported that their CBP project details have been passed up to high-level management, who has adopted the building project as a prototype for future building construction. The same organization indicated that the CBP program gave them an opportunity to enhance and optimize measures they already employed in their building practice and fine-tune their process for energy efficiency.

Finally, when asked about actual energy savings versus modeled or expected savings, the majority of CBP partners reported that it was too soon to tell, as their building projects have not had enough time to yield robust data. Three respondents reported that they were realizing predicted energy savings, and one partner reported their savings was very close to that predicted. One partner reported there had been a default setting in the control sequence of the HVAC system, causing the system to continuously operate. However, the issue has been corrected and they are now expecting modeled and actual savings to align. Also in the follow-up interviews, one partner indicated that the solar photovoltaic system, installed as part of their new construction EEM package, sent enough electricity to the grid in May 2013 to make the building net energy positive, in terms of electricity consumption. 


\subsection{Market Penetration Potential}

Another primary objective of this study aimed to gain a better understanding of replication efforts underway by partners, taking EEMs from their specific projects into the rest of their building portfolios. Analysis of these efforts provides foundations for broader market analysis of the potential of the CBP program on total commercial building sector energy consumption and cost savings. This section uses the diffusion of innovations theory to explore possible market impacts of the CBP program throughout the commercial building sector in the United States.

Data collected through a questionnaire mechanism and company interviews provide insight into the replication efforts underway by each CBP partner. In an effort to better understand the potential impacts on the broader commercial market, this section explores replication into the entire commercial building sector utilizing a diffusion model.

\subsection{Diffusion Theory}

Traditional diffusion of innovations theory was developed in the 1960's by Everett Rogers as a means to describe the process of technical change and advancement of innovation within a culture over time (Rogers, 1995). Technology diffusion happens over five primary "adopter" categories, resulting in an S curve when analyzed over time. New ideas developed by innovators are introduced into the market by early adopters, then through the early and late majorities, and eventually the laggards (Rogers, 1995). The result is a description of the process, based largely on communication channels, in which new products become adopted by a population or society. Figure 14 presents the classic diffusion curve and adopter categories.

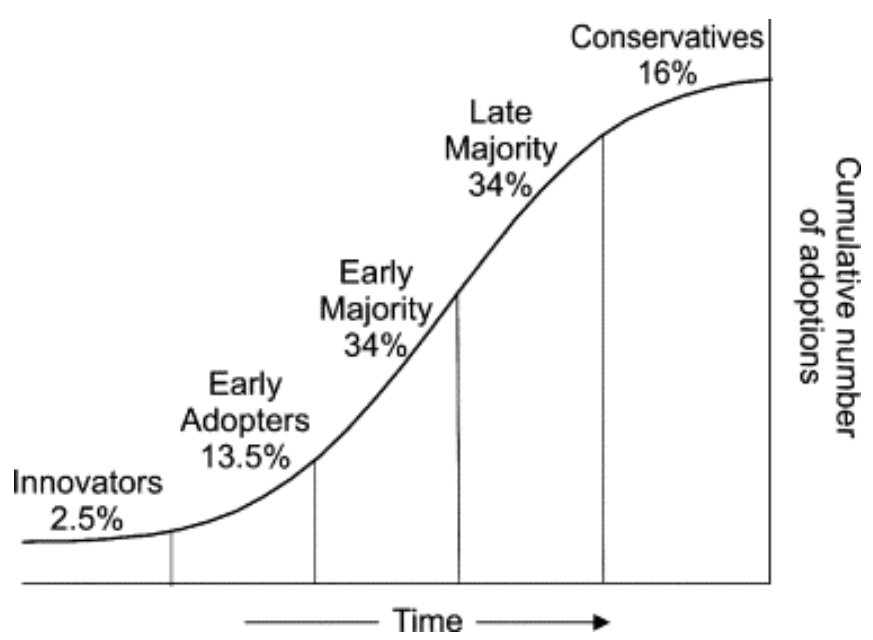

Figure 14. Traditional Diffusion Curve (Patenaude, 2011)

Mathematically, the first widely-adopted quantitative model describing the new product or technology diffusion process was developed by Frank Bass in 1969. Known as the Bass diffusion model, the formulation is based upon a differential equation representing the number or market share of innovation adopters over a period of time, incorporating both internal and external influences (Bass, 2004). Internal 
influences are impacts of media, government and other broad adoption efforts, and external influences involve social interaction (Bass, 2004). Both are represented as coefficients.

Diffusion models are widely used in many industries as a means of forecasting market penetration of new technologies. The general form of the Bass model is given in Equation 1, where:

$N(t)$ is the cumulative number of adoptions at time $(t)$

$M$ is the market potential, a constant

$p$ is the coefficient of innovation

$q$ is the coefficient of imitation or internal influence (Bass, 1969).

$$
\frac{d N(t)}{d t}=\left(p+\frac{q}{M} \cdot N(t)\right) \cdot(M-N(t))
$$

The Bass model may be solved explicitly for the fraction of the market penetrated, $F(t)$, by assuming the initial number of adopters at $t=0$ is 0 . This results in a formula that may be used to estimate the cumulative adoptions as a function of $q$ (coefficient of imitation) and $p$ (coefficient of innovation).

$$
F(t)=\frac{1-\exp (-(p+q) t)}{1+\left(\frac{q}{p}\right) \exp (-(p+q) t)}
$$

\subsection{Methodology}

The diffusion models in this study have been used to estimate the long-term impact of the CBP efforts (within partner portfolios and the broader market) by modeling replication of the CBP program approach over time. To understand the best way to adapt the Bass model for this purpose, the literature for the diffusion of energy-efficient technologies in buildings was reviewed. The general approach consisted of calibrating the Bass model for a specific application, in this case commercial building construction. To calibrate the Bass model, a larger data set was needed so the USGC certification database was considered.

Different versions of the Bass model have been used to predict energy efficiency technology diffusion in the building sector by several authors. The work of Elliott et al. (2004) used a modified version for specific building technologies including condensing furnaces, compact fluorescent lights, and lowemissivity windows. The authors determined coefficients ( $p$ and $q$ ) and market potential for each individual building technology or energy measure separately. Andrews and Krogmann (2009) compared 1992 and 2003 CBECS data to explore key technology diffusion trajectories and energy intensities over time. In more recent work, Kok et al. (2011) analyzed green building diffusion in U.S. property markets, estimating that $30 \%$ of commercial office space in large metropolitan areas is ENERGY STAR certified, and $11 \%$ LEED certified.

The work of Fisher and Pry (Fisher, 1971) is similar to the work of Bass, but differs in the initial conditions used to solve the equation. The Fisher Pry model for technology diffusion is based on an estimate for 50\% market penetration rate. Yudelson (Yudelson, 2007) used the Fisher Pry model to 
estimate the market penetration of green buildings as a unit, rather than individual EEMs. The model is also dependent on several coefficients that were derived from exploration of historic LEED certifications.

For application to CBP buildings, this study adopted the diffusion process based on the model developed by Bass (Bass, 1969) but treats the entire energy-efficient building as the technology to be diffused rather than a specific EEM. To determine the appropriate coefficients for this model, the market penetration of green buildings was examined using the methodology of Yudelson. Specifically, the empirical modeling was based on the market data available for LEED certification.

\subsubsection{Energy Efficiency Building Diffusion Data with Bass Model}

To determine the Bass model application to energy efficiency for a whole building, the largest existing data set found was the USGBC LEED certification database. The current study is not focused on the validity of the USGBC system, and considered it only as an energy efficiency program that operates at the whole-building level in a manner comparable to the CBP program. The USGBC dataset has a much larger number of data points; roughly 15,500 certified buildings are included in the dataset at the time of this study (USGBC, 2013).

The data set was downloaded from the USGBC website and the Yudelson estimate was compared to actual LEED certifications as shown in Figure 15. The red data represents the USGBC data (USGBC 2013), and the blue line is the Yudelson estimated diffusion profile presented in his 2005 analysis. 


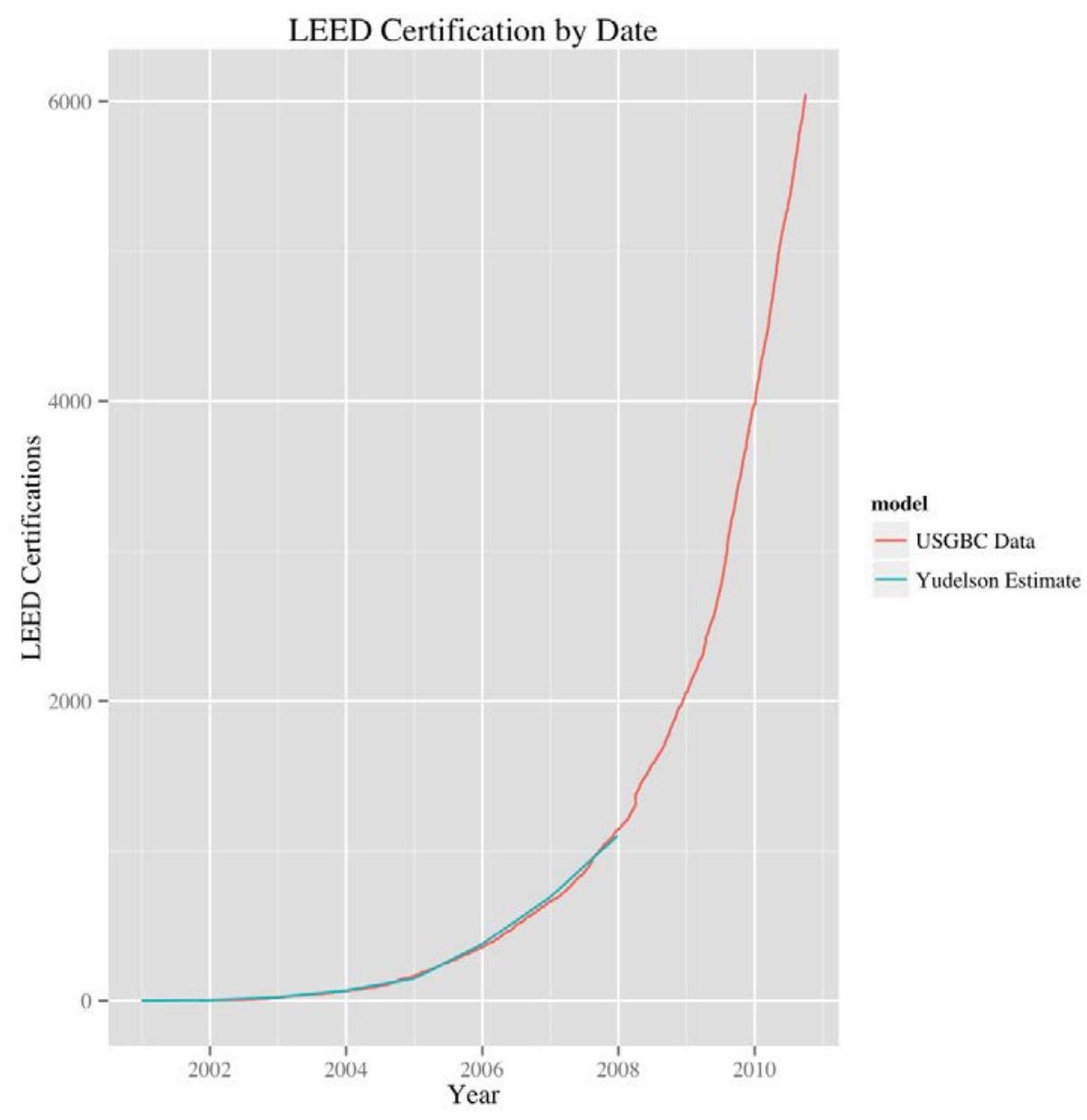

Figure 15. Raw Diffusion Data and the Yudelson Model

The Yudelson diffusion model over-predicted the number of LEED certifications in the first years of the model, and then improved through 2007 as shown in Table 3 and Figure 14. However, the general shape of the diffusion curve closely matches the historical data for subsequent years. One limitation of the Yudelson technique using the Fisher-Pry model was the formulation of the diffusion equation, which required an initial condition estimate of the $50 \%$ penetration rate. The Bass diffusion model, to be discussed next, avoids this issue and is considered more appropriate for this study.

The raw data from the USGBC were fit to the Bass model using a range of $p$ (coefficient of innovation) and $q$ (coefficient of imitation) parameters with a range of $p$ between 0.000001 and 0.5 based on the results of Elliott et al. (Elliott et al., 2004). Similarly the value of q varied between 0.005 and 1 . The fit of the $p$ and $q$ parameters was evaluated using the traditional definition of $R^{2}$. In the following equation, $y_{i}$ is the observed raw data, $\bar{y}$ is the mean of the raw data, and $f_{i}$ is the value predicted by the Bass model for each time point.

$$
R^{2}=1-\frac{\sum_{i}\left(y_{i}-f_{i}\right)^{2}}{\sum_{i}\left(y_{i}-\bar{y}\right)^{2}}
$$


Table 2 provides a summary of the modeling inputs and outputs. The final $p$ and $q$ coefficients are based on maximizing the $R^{2}$ coefficient. Using a straightforward grid search methodology, a 100x100 matrix of $\mathrm{p}$ and q parameters was generated and the predicted number of adoptions was calculated using the Bass model for each pair of parameters. The $R^{2}$ coefficient was evaluated for each parameter pair in the matrix and the final pair of parameters was selected on the basis of the best model fit to the raw data.

The maximum market potential (number of buildings) was estimated based on the average commercial buildings size during the time frame of data considered and the estimated total amount of floor space. The market potential is based only on new commercial construction because only a small portion of the USGBC building database is comprised of building renovations (only 5,887 of 41,505 buildings in the USGBC data base are tagged as "Existing Buildings"). The total number of buildings $(m)$ matches fairly well with the number estimated by Yudelson (2007).

Table 2. Bass Model Parameters Determined from the Raw Data

\begin{tabular}{|l|l|l|}
\hline \multicolumn{1}{|c|}{ Bass Model Parameter } & \multicolumn{1}{|c|}{$\begin{array}{c}\text { Value Determined } \\
\text { (Bass Traditional) }\end{array}$} & Source \\
\hline$p$ - coefficient of innovation & $8.42 \mathrm{e}-5$ & Data fitting \\
\hline$q$ - coefficient of imitation & 0.359 & Data fitting \\
\hline $\begin{array}{l}m \text { - maximum market } \\
\text { potential (number of } \\
\text { buildings) }\end{array}$ & $1,068,493$ & $\begin{array}{l}\text { Total new commercial buildings constructed between } \\
2000-2013, \text { estimated from } 14,700 \mathrm{ft}^{2} / \mathrm{building} \text { and } \\
15.6 \times 10^{9} \mathrm{ft}^{2}(\text { EIA, 2008; DOE, 2012b) }\end{array}$ \\
\hline $\begin{array}{l}R^{2} \text { - coefficient of } \\
\text { determination }\end{array}$ & 0.987 & $\begin{array}{l}\text { Calculated to compare fit of Bass model with USGBC } \\
\text { data }\end{array}$ \\
\hline
\end{tabular}

The final Bass model parameters predict the correct trend for certification in the later years, but show a tendency to over-predict diffusion in the first few years of the LEED program. Figure 16 shows the Bass model and raw data on the same scale. While over-predicting the behavior in the first 8 years is an issue for the Bass model, it is the slope of the model in the last years that is considered to be the most important result. When using the model to make predictions of market diffusion, the principal variable of interest is the cumulative number of adoptions (buildings). This value is well represented by the Bass model, with the number of predicted energy-efficient buildings only slightly lower than the actual number in 2012 (as shown in the last row of Table 3).

Table 3. Comparison of the USGBC Database with Two Diffusion Models. Data Shown are the Cumulative Number of Buildings (Actual) and Predicted for Each Model.

\begin{tabular}{|l|l|l|l|}
\hline Year & \multicolumn{1}{|c|}{$\begin{array}{c}\text { USGBC Raw } \\
\text { Data (Actual) }\end{array}$} & $\begin{array}{c}\text { Yudelson } \\
\text { Prediction }\end{array}$ & $\begin{array}{c}\text { Bass Model } \\
\text { Prediction } \\
\text { (Present Work) }\end{array}$ \\
\hline 2005 & 358 & 377 & 853 \\
\hline 2007 & 1,145 & 1,104 & 2,007 \\
\hline
\end{tabular}




\begin{tabular}{|l|l|l|l|}
\hline 2010 & 6,674 & - & 6,350 \\
\hline 2012 & 13,224 & - & 13,221 \\
\hline
\end{tabular}

The conclusion from our estimation of the Bass model is that it appears to satisfactorily represent the historical cumulative construction metrics for whole-building energy efficiency programs. The Bass model parameters developed also can provide perspectives related to the long-term, future market diffusion of energy efficiency programs.

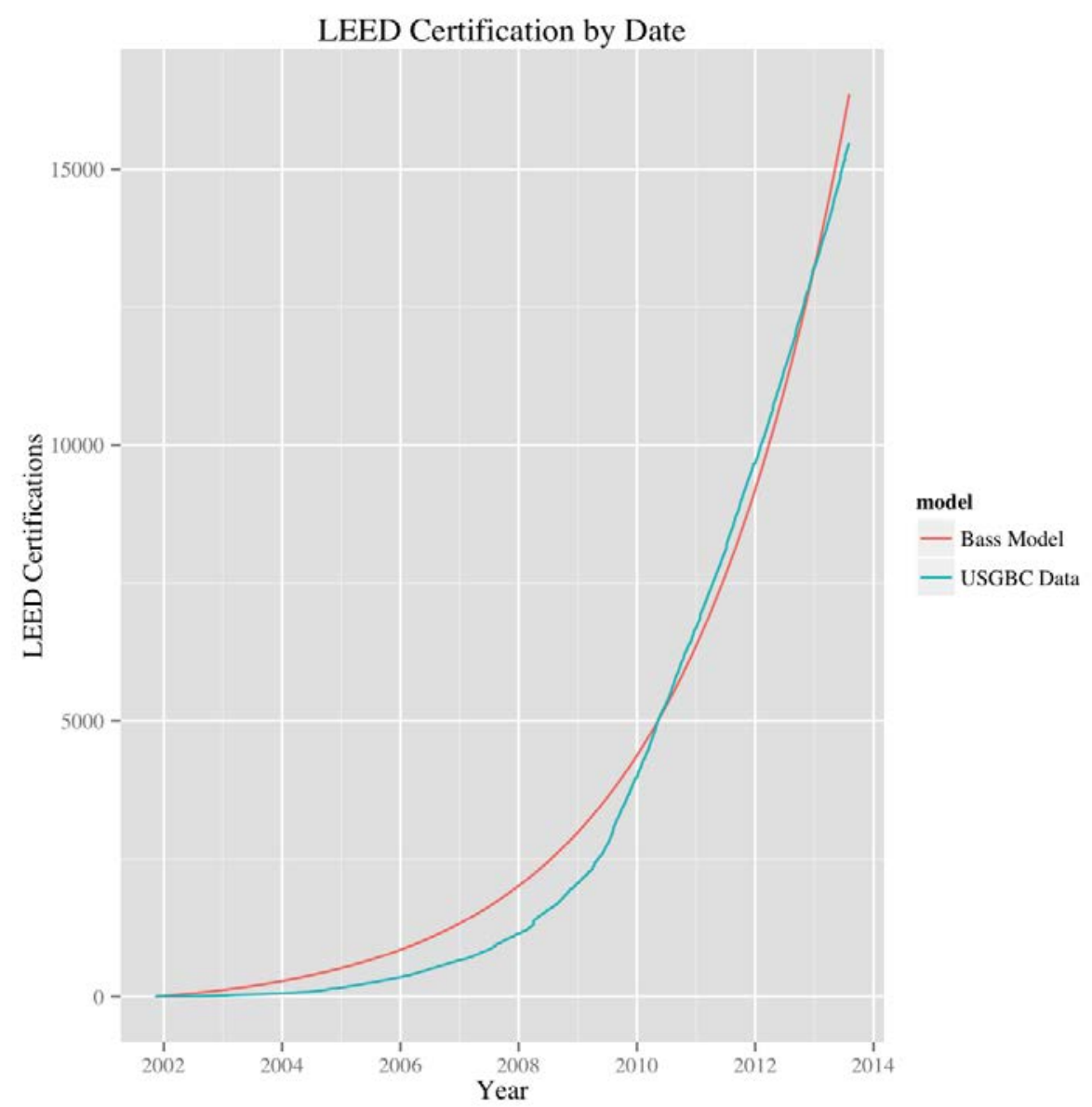

Figure 16. Raw Diffusion Data and the Bass Model Fit for Our Study

\subsubsection{Application of the Bass Diffusion Model to CBP}

Two Bass models (CBP Construction and Market Bass Model) were developed which resulted in a large difference between modeled outputs. The CBP Construction model (conservative) was developed using data from CBP partners only, with the output representing the maximum number of buildings impacted normalized by total number of buildings in CBP partner portfolios. The Market Bass model (optimistic) was developed by extrapolating the dataset out to the broader market, and represents market diffusion potential for the full partner portfolios based on the observed diffusion of other green building programs. This section explains both models and presents outputs from the analysis. 
The previous section outlines the development of a Bass diffusion model based on the most comprehensive existing database of a building-scale energy efficiency program. The calibrated Bass model was then utilized to provide a mechanism to determine the best case impacts of the CBP program. In order to do this, the research team developed a Bass model based on building-level implementation of EEMs. Other studies have looked at specific EEMs (see: Andrews and Krogmann, 2009a; Elliott et al., 2004; McCoy et al., 2010).

Table 4 presents the parameters for determining model inputs. Since the focus of this analysis is on the market potential for CBP program replication, the research team determined the normalizer $(m)$ should focus on market potential based on maximum number of buildings within the entire CBP portfolio. This was calculated as the quotient of total existing CBP partner portfolio square footage and average commercial building size in the U.S., giving an estimate of 250,709 buildings to represent the market maximum. Because the research team only had access to data on the existing portfolios of CBP partners, the final analysis is conservative, and it is probable that partner portfolios will increase over time.

Two distinct Bass diffusion models were then used to bind the eventual diffusion of the CBP program. The "Market Bass" model is simply a projection of the Bass model using the $q$ and $p$ parameters determined from the larger USGBC data set. This model is deemed to represent the way one other building-scale energy efficiency programs has diffused in the commercial buildings sector. A second Bass model, termed the "CBP Bass" model is a version of the model analyzing the CBP partners only, where $q$ and $p$ parameters were determined from the actual CBP construction data while maximizing the $R^{2}$ coefficient. The parameters used in the CBP Bass model are shown in Table 4.

Table 4. Bass Model Parameters Determined from the CBP Data.

\begin{tabular}{|l|l|l|}
\hline \multicolumn{1}{|c|}{ Bass Model Parameter } & \multicolumn{1}{|c|}{$\begin{array}{c}\text { Value Determined } \\
\text { (Bass Traditional) }\end{array}$} & \multicolumn{1}{c|}{ Source } \\
\hline$p$ - coefficient of innovation & $1.344828 \mathrm{e}-5$ & Data fitting \\
\hline$q$ - coefficient of imitation & 0.2448 & Data fitting \\
\hline $\begin{array}{l}m \text { - maximum market } \\
\text { potential (number of } \\
\text { buildings) }\end{array}$ & 250,709 & $\begin{array}{l}\text { Total new commercial buildings constructed by CBP } \\
\text { partners, estimated from total CBP partner portfolios } \\
\left(\mathrm{ft}^{2}\right) \text { and } 14,700 \mathrm{ft}^{2} / \text { building (EIA, 2008) }\end{array}$ \\
\hline $\begin{array}{l}R^{2} \text { - coefficient of } \\
\text { determination }\end{array}$ & 0.951 & $\begin{array}{l}\text { Calculated to compare fit of Bass model with } \\
\text { USGBC data }\end{array}$ \\
\hline
\end{tabular}

Figure 17 and Table 5 present diffusion potential of the CBP program by number of buildings, predicted using the CBP Bass model. The projection range is from 2008 to 2020 and the diffusion rate is the percentage of total buildings in CBP partner portfolios based on the Bass model. The raw CBP construction data was calculated as the cumulative CBP buildings based on data gathered and monitored by ANL, LBNL, NREL and PNNL. Each lab compiled and tracked partner data which included project specific information, overall partner portfolio square footage, building type, location, project completion date (actual or anticipated), and a synopsis of EEMs. 


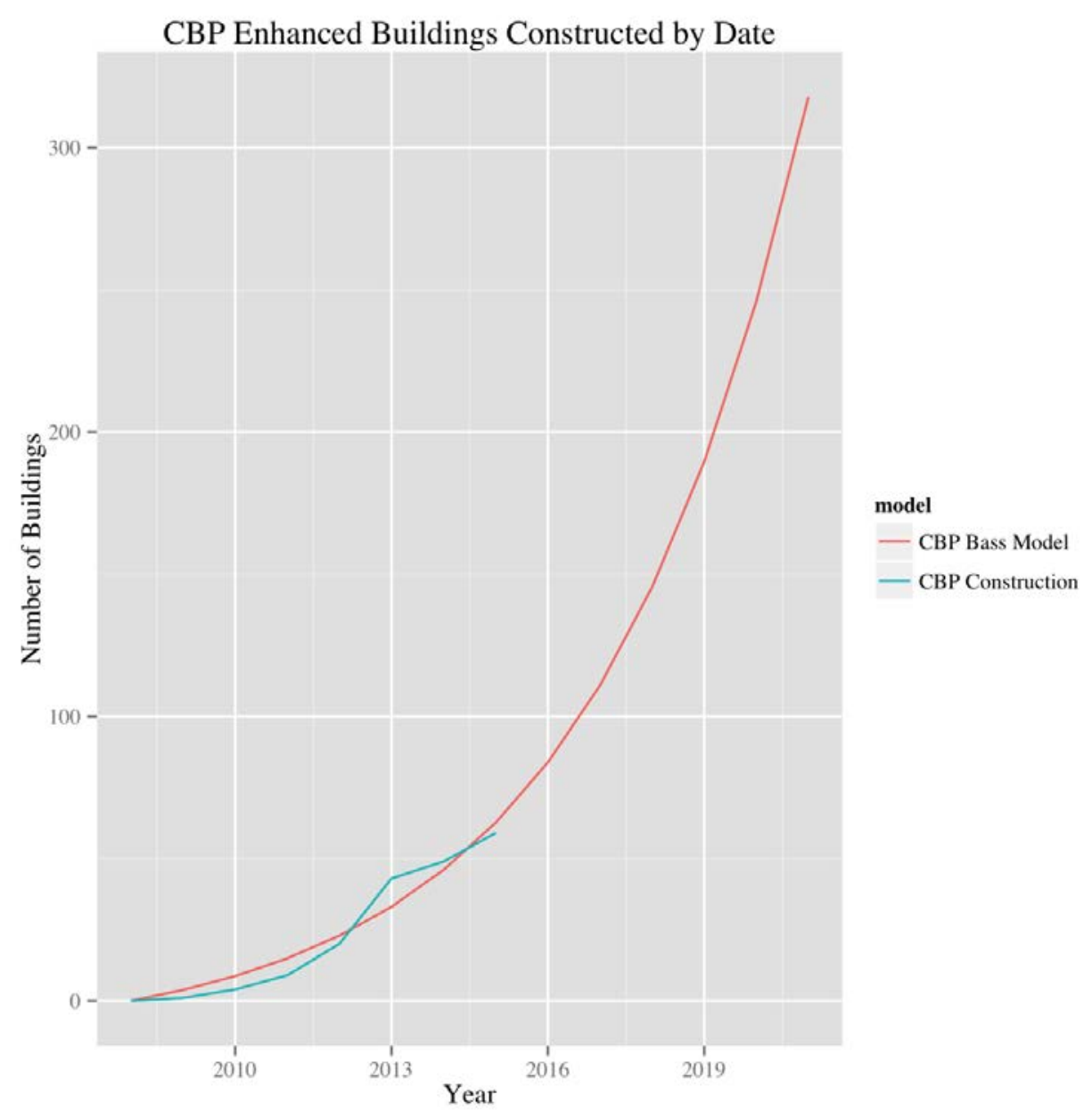

Figure 17. CBP Diffusion Prediction Using the Bass Model, $R^{2}=0.95$.

Figure 18 shows the CBP Bass and CBP Construction diffusion model predictions through the year 2030. The Market Bass model (optimistic scenario) represents a best case scenario for CBP diffusion based on the way the commercial building sector has adopted another larger, but somewhat similar, whole-building energy efficiency program. The CBP Bass model represents a conservative (worst case scenario) based only on the CBP enhanced buildings constructed to date.

Table 5 shows the comparison of the two Bass models with the CBP construction data. The CBP Bass model does an excellent job predicting the construction in 2015 ("actual" data include projections of completed buildings from LBNL, NREL and PNNL), high by only a few buildings. The conservative model indicates that nearly 3,000 buildings will be enhanced by the CBP program by 2030 . The more optimistic diffusion model indicates that CBP enhancements could penetrate as many as 97,000 buildings by the same year. The discrepancy between the optimistic and worse case is due to the large difference in input data.

It is important to note that the actual number of projects presented below include only partner buildings directly involved in CBP, not replication efforts already underway by partners. This implies that the 
Market Bass model (optimistic scenario) may be closer to the actual number of buildings impacted by CBP.

Table 5. Comparison of CBP Construction to Date with Bass Prediction. Data Shown are the Cumulative Number of Buildings (Actual) and Predicted for Each Model.

\begin{tabular}{|l|l|l|l|}
\hline Year & \multicolumn{1}{|c|}{$\begin{array}{c}\text { CBP Construction } \\
\text { (Number of Buildings } \\
\text { Actual) }\end{array}$} & $\begin{array}{c}\text { Market Bass Model - } \\
\text { Optimistic Scenario } \\
\text { (Number of Buildings } \\
\text { Predicted) }\end{array}$ & $\begin{array}{l}\text { CBP Bass Model - Worst } \\
\text { Case Scenario (Number of } \\
\text { Buildings Predicted) }\end{array}$ \\
\hline 2012 & 20 & 188 & 23 \\
\hline 2015 & 59 (scheduled completion) & 665 & 63 \\
\hline 2030 & - & 97,101 & 2,957 \\
\hline
\end{tabular}

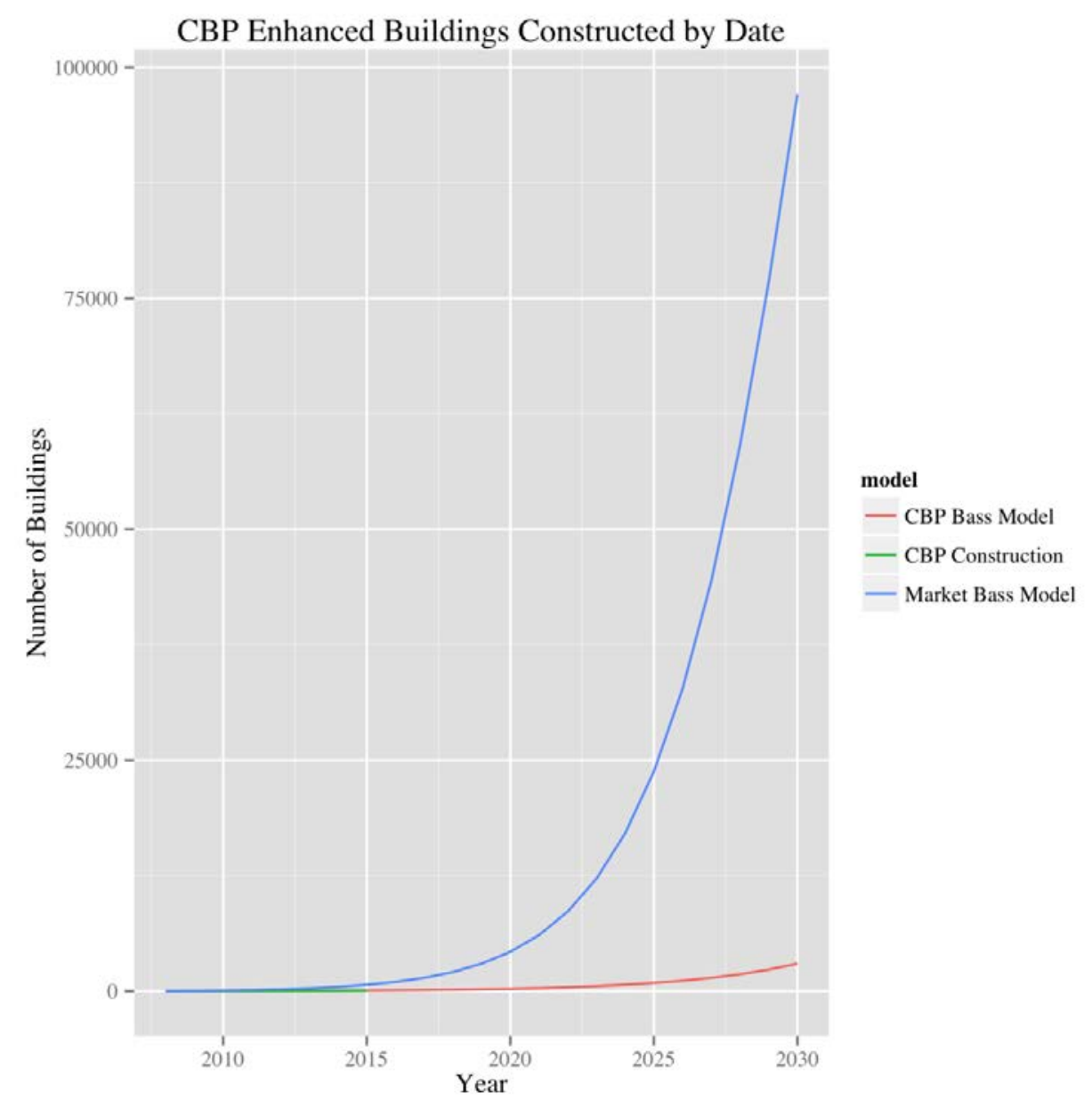

Figure 18. CBP Market Penetration Prediction Using the Bass Model 
By 2030, the diffusion model forecasts that a range of 2,957 to 97,101 buildings will be impacted by the CBP program through partner replication efforts, representing over $22 \%$ of all buildings in partner portfolios. This translates to 43.5 million to 1.4 billion square feet of commercial building floor space. Previous analysis efforts of CBP projects modeled energy use intensity (EUI) reductions of $53 \mathrm{kBtu} / \mathrm{ft}^{2}$ for new construction projects overseen by PNNL (Baechler et al., 2012). In an effort to extrapolate broader energy savings data, the research team compared this decrease in modeled CBP EUIs with median EUI data from CBECS. Based on this analysis, the energy savings potential is between 2.3 and 77 trillion Btus annually.

As part of this study, we ran a second savings calculation based on ENERGY STAR's portfolio manager data trends instead of CBECS. Energy use benchmarking is available for office, retail, K-12 school and hotel buildings, which includes median EUIs for each building type (ENERGY STAR, 2012). The median EUIs for office, retail and hotel buildings were averaged and calculated with EUI reductions of 53 $\mathrm{kBtu} / \mathrm{ft}^{2}$ (from Baechler et al., 2012). The resulting energy savings numbers were very similar to the comparison with CBECS, ranging between 2.3 and 75 trillion Btus annually. 


\subsection{Findings}

The findings and discussion within this section are organized according to the two primary research agendas and analytical tasks. The first section presents primary findings and discussion about CBP partner replication trends, and the second section discusses market diffusion findings and market potential for the CBP approach in new and retrofit construction projects.

\subsection{CBP Partner Replication Findings}

Questionnaire and interview data indicated that all CBP partners are replicating some or all of the technologies or approaches utilized in the CBP program. Table 1 and Figure 10 illustrate these replication trends by EEM. In follow-up conversations, partners elaborated on replication efforts, motivations and future plans for continued replication efforts. Based on questionnaire and interviews, the following represent the primary findings of CBP replication.

Finding 1: The CBP program has provided a testbed for future construction projects within the partner portfolio

Of all the technology options and approaches to saving energy within their building or retrofit projects, $100 \%$ of CBP partner questionnaires indicated three EEMs would be replicated throughout all construction projects: low-wattage exit signs, occupancy sensors and energy management systems. The study team was particularly interested in why these specific technologies had a $100 \%$ replication rate and asked partners specifically about this in follow-up interviews. Respondents indicated that their CBP project provided a testbed facility for determining which EEMs provide the greatest energy and cost savings for their building type. Instead of a prescriptive approach to energy and cost savings, partners can utilize lessons learned from the CBP program to implement in other buildings.

This testbed approach allows CBP partners to add to their existing protocols for green buildings and energy efficiency. Many partners participating in green building programs such as LEED indicated the CBP program allowed them to identify specific technologies to incorporate into their existing approaches for green building. The three EEMs that are being replicated by $100 \%$ of CBP partners, (low wattage exit signs, occupancy sensors, and programming, commissioning and optimization efforts) fall into this category.

Other technologies that will be highly replicated by CBP partners are interior and exterior LED lighting technologies. One partner indicated that the CBP program provided insight into the savings potential from these technologies which were not understood before CBP program participation. Another partner indicated that LED lighting technologies were a primary lesson learned and will be implemented into other buildings.

Finding 2: The CBP program helped optimize the implementation of EEMs for cost and energy savings

Measurement and verification $(\mathrm{M} \& \mathrm{~V})$ is an important factor in the CBP program, along with initial energy modeling and analysis used by consultants to determine optimal approaches for cost and energy savings. CBP projects utilized a variety of simulation tools, including EnergyPlus, DOE2 and TraneTrace. Based on modeling, CBP partners implemented a suite of technologies specifically optimized for their building, with the mix varying greatly among projects. An important strength of the CBP program, based 
on questionnaire data and interviews, was this comprehensive look at building systems and the approach to building and retrofit measures.

One partner provided specific examples about the focus on specific building operations, identifying plug load reductions thanks to energy modeling. This partner noted that plug loads now represent the greatest energy savings potential within the company portfolio, a fact unknown before CBP participation. They noted "We didn't realize how much additional energy could be saved from plug loads; CBP allowed us to analyze every machine plugged in, and optimize a package of technologies to decrease the loads." This approach is a critical component for realizing the ambitious goals of CBP; $50 \%$ energy reduction in new construction, and 30\% for retrofits (DOE 2011b).

Technology selection through modeling also helps organizations monitor the performance of their energy systems over the long term. One aspect built into the CBP program is a comprehensive process for $\mathrm{M} \& \mathrm{~V}$. Questionnaire and interviews indicate that some CBP partners did not previously have a system for $\mathrm{M} \& \mathrm{~V}$, and that while energy saving technologies were implemented, they were not monitored for performance after construction or installation. $\mathrm{M} \& \mathrm{~V}$ protocols established through the CBP program provide foundations for organizations to monitor the long-term performance of EEMs, providing data necessary to ensure that system operation is optimized.

Finding 3: CBP partners are motivated by cost savings more than other benefits

All CBP partners indicated that cost savings was the primary motivation for investing in green building technologies, including energy efficiency. In some cases, partners indicated that energy expenditures were in the top five in terms of overall operation budgets. CBP partners made it clear both in questionnaire results and follow-up interviews that part of the success they realized through the CBP program was hinged on cost savings for their organization. Outside of direct reductions in energy expenditures, organizations also noted they realized lower maintenance, increased employee productivity and increased building comfort.

Although motivated primarily by energy savings, $100 \%$ of CBP participants interviewed for this study indicated their organization had sustainability protocols. Such protocols were also motivators for CBP partners to participate in the CBP program, but secondary to direct cost savings. Partners indicated their projects will be used in media such as press releases and other materials promoting their organization's attention to sustainability.

\subsection{Market Potential Findings}

This study used a diffusion model to estimate the long-term impact of the CBP efforts by modeling replication of the CBP program approach over time. This required creating a model that was effective in analyzing implementation of EEMs on a whole-building basis, as opposed to determining diffusion of specific EEMs. The general approach consisted of calibrating the Bass model utilized in previous studies to assess EEMs, to a broader representation of whole-building energy efficiency approaches. To calibrate the Bass model, a larger data set was needed so the USGBC certification database was used.

The model was created by calibrating raw certification data from the USGBC, and using the resulting coefficients to predict the diffusion of the CBP program. The conclusion from the analysis of the Bass model when applied to the USGBC database is that this method of prediction may be used to adequately capture cumulative construction metrics for that program, which is focused on whole-building energy efficiency, making it a good fit for CBP program analysis. The Market Bass model parameters developed 
also provide an optimistic perspective for the type of market diffusion that may occur based on energy efficiency programs.

Figure 19 shows both Bass model predictions through the year 2030. The Market Bass model represents a best case scenario for CBP diffusion. The CBP Bass model represents a conservative (worst case scenario) based only on the CBP enhanced buildings constructed to date.

The CBP Bass model does an excellent job predicting current construction trends, high by only a few buildings. This model indicates that nearly 3,000 buildings may be enhanced by the CBP program by 2030. The more optimistic diffusion model indicates that CBP enhancements could penetrate almost 100,000 buildings by 2030 .

It is important to note that the actual number of projects presented below include only partner buildings directly involved in CBP, not replication efforts already underway by partners. This implies that the Market Bass model may better represent the future number of buildings impacted by CBP.

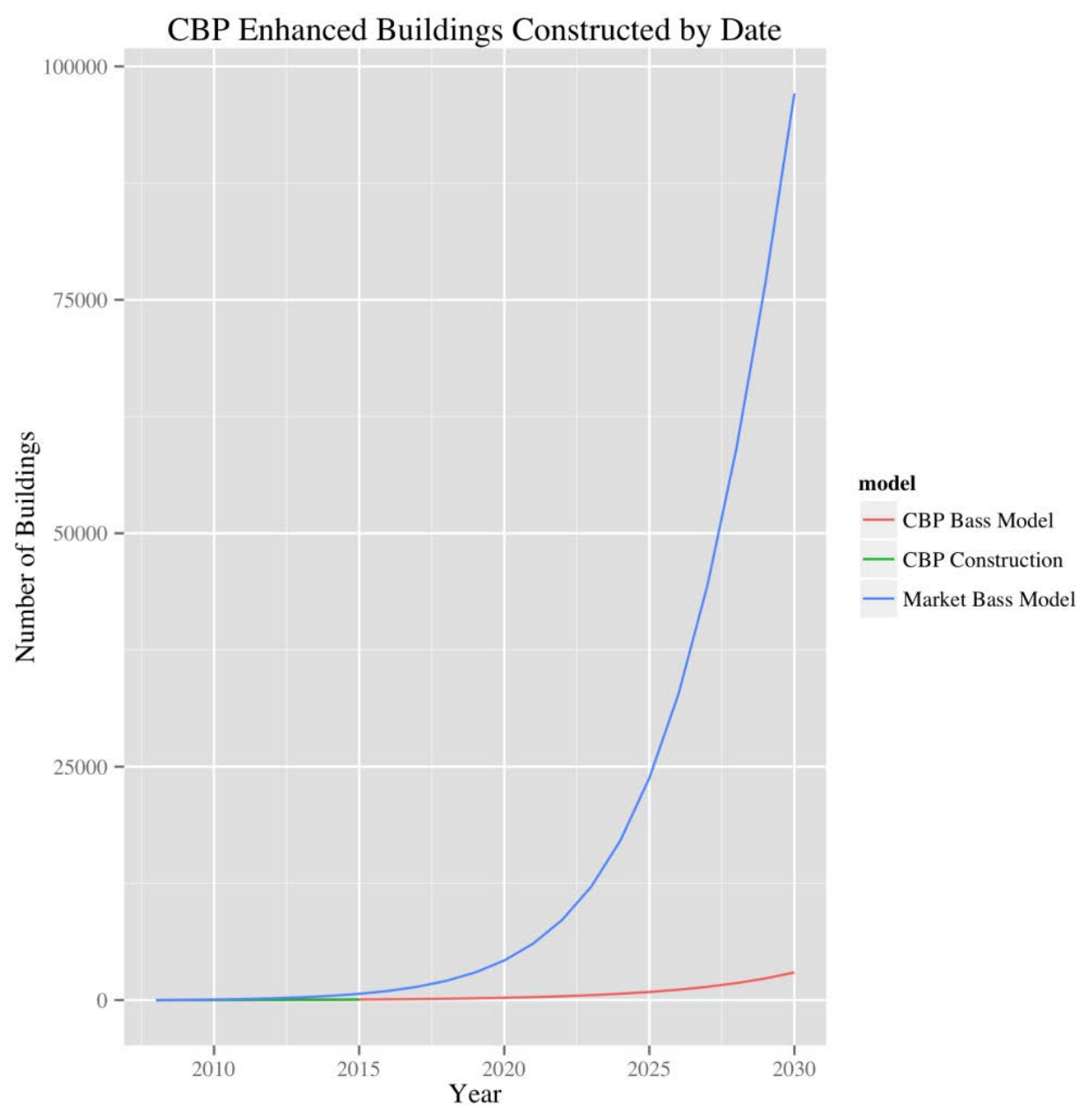

Figure 19. CBP Market Penetration Prediction Using the Bass Model 
The analysis indicates the CBP program model is a very effective way to enhance energy savings in the commercial building sector. The partners report that replication of specific EEMs and the overall "optimized" approach will be utilized for future construction. The CBP enhanced buildings will diffuse through the partner building stock and provide significantly greater benefits than those of traditional energy programs because the solutions are focused on each partner. Diffusion could be as high as nearly 100,000 buildings by 2030 , each operating with 30 to $50 \%$ lower energy use as compared to conventionally constructed or operated buildings. 


\section{References}

110 USC Sec. 1305. (2007). Energy Independence and Security Act of 2007 (EISA). Public Law 110-140.

Allcott, H., \& Mullainathan, S. (2010). "Behavioral science and energy policy." Science, 327(5970), 1204-1205.

Andrews, C. J., and Krogmann, U. (2009a). "Explaining the adoption of energy-efficient technologies in U.S. commercial buildings." Energy and Buildings, 41, 287-294.

Andrews, C. J., and Krogmann, U. (2009b). "Technology diffusion and energy intensity in US commercial buildings." Energy Policy, 37, 541-553.

ASHRAE--American Society of Heating, Refrigeration and Air Conditioning Engineers. (2011). ASHRAE Guideline 0: The Commissioning Process. 2011.09.28.

Athalye, R. A., Xie, Y., Liu, B., \& Baechler, M. C. (2012). A Case Study: Using Integrated Approach to Design a Net-Zero Bank Branch (No. PNNL-SA-85026). Pacific Northwest National Laboratory (PNNL), Richland, WA (US).

Baechler, M., Dillon, H., and R. Bartlett. (2012). Commercial Building Partners Catalyze Energy Efficient Buildings Across the Nation. Paper presented at the 2012 ACEEE Summer Study on Energy Efficiency in Buildings, Pacific Grove, CA.

Bass, F. M. (1969). “A new product growth for model consumer durables.” Management Science, 15 (5), 215-227.

Belzer, D. B. (2009). Energy Efficiency Potential in Existing Commercial Buildings: Review of Selected Recent Studies. PNNL-18337. Pacific Northwest National Laboratory, Richland, WA.

DOE-U.S. Department of Energy. (2012a). Buildings Energy Data Book. Chapter 1: Buildings Sector. Energy Efficiency and Renewable Energy, U.S. Department of Energy, Washington D.C. http://buildingsdatabook.eren.doe.gov/ChapterIntro1.aspx?1\#1.

DOE-U.S. Department of Energy. (2012b). Buildings Energy Data Book. 3.2: Commercial Sector Characteristics. Energy Efficiency and Renewable Energy, U.S. Department of Energy, Washington D.C. http://buildingsdatabook.eren.doe.gov/TableView.aspx?table=3.2.1.

http://buildingsdatabook.eren.doe.gov/ChapterIntro1.aspx?1 - 1

DOE-U.S. Department of Energy. (2012c). Buildings Energy Data Book.. 3.1: Commercial Delivered Energy Consumption Intensities, by Vintage. Energy Efficiency and Renewable Energy, U.S. Department of Energy, Washington D.C. http://buildingsdatabook.eren.doe.gov/TableView.aspx?table=3.1.8.

DOE_U.S. Department of Energy. (2011b). Commercial Building Partnerships: Mainstreaming Energy Efficient Strategies. U.S. Department of Energy, Washington D.C.

http://apps1.eere.energy.gov/buildings/publications/pdfs/alliances/cbp_factsheet.pdf. 
DOE-U.S. Department of Energy (2011a). Federal Sustainable Building and Campus Requirements. Federal Energy Management Program, U.S. Department of Energy, Washington D.C. http://www1.eere.energy.gov/femp/program/sustainable_requirements.html

EIA-U.S. Energy Information Administration. (2012). Annual Energy Review 2011. DOE/EIA0384(2011). U.S. Energy Information Administration, Washington, D.C. http://www.eia.gov/totalenergy/data/annual/pdf/aer.pdf.

EIA-U.S. Energy Information Administration. (2008). Commercial Building Energy Consumption Questionnaire (CBECS). U.S. Energy Information Administration, Washington, D.C. http://www.eia.gov/emeu/cbecs/cbecs2003/detailed_tables_2003/detailed_tables_2003.html.

EIA-U.S. Energy Information Administration. (2008). Commercial Building Energy Consumption Questionnaire (CBECS). Summary Table for All Buildings. U.S. Energy Information Administration, Washington, D.C.

http://www.eia.gov/consumption/commercial/data/archive/cbecs/cbecs2003/detailed_tables_2003/2003set 1/2003html/a1.html.

Elliott, D. B., Anderson, D. M., Belzer, D. B., Cort, K. A., Dirks, J. A., and Hostick, D. (2004). Methodological Framework for Analysis of Buildings-Related Programs : The GPRA Metrics Effort. Pacific Northwest National Laboratory, Richland, WA.

ENERGY STAR. (2012). Portfolio Manager Data Trends. Retrieved from http://www.energystar.gov/buildings/about-us/research-and-reports/portfolio-manager-datatrends.

Fisher, J. C., and Pry, R. H. (1971). "A simple substitution model of technological change." Technological Forecasting and Social Change, 3, 75-88.

Gillingham, K., Newell, R. G., and Palmer, K. (2009). "Energy efficiency economics and policy" (No. w15031). National Bureau of Economic Research. Washington, D.C. http://www.rff.org/documents/rffdp-09-13.pdf.

Howarth, B., R., Haddad, B. M., and Paton, B. (2000). "The economics of energy efficiency: insights from voluntary participation programs.” Energy Policy, 28 (6), 477-486.

Khanna, M., Koss, P., Jones, C. and Ervin, D. (2007). "Motivations for voluntary environmental management." Policy Studies Journal, 35, 751-772.

Kneifel, J. (2010). "Life-cycle carbon and cost analysis of energy efficiency measures in new commercial buildings." Energy and Buildings, 42 (3), 333-340.

Kok, N., McGraw, M., and Quigley, J. M. (2011)." The diffusion of energy efficiency in building." American Economic Review, 101(3), 77-82.

McCoy, A., Badinelli, B., Koebel, T., and W. Thabet. (2010). "Concurrent commercialization and newproduct adoption for construction products." European Journal of Innovation Management, 13(2), 222243.

Patenaude, G. (2011). "Climate change diffusion: While the world tips, business schools lag." Global Environmental Change, 21(1), 259-271. 
Rogers, E. M. (1995). Diffusion of Innovations. Fourth Edition. New York, NY: The Free Press.

State of California. (2002). State of California's Sustainable Building Technical Group. Sustainable Building Guidelines. Retrieved from http://www.calrecycle.ca.gov/greenbuilding/design/guidelines.htm

USGBC_-United States Green Building Council. (2013). Online Project Directory. Retrieved from http://www.usgbc.org/projects on 8/5/2013.

Xie, Y., Liu, B., Athalye, R., Baechler, M., and Sullivan, G. (2012). Measuring and Understanding the Energy Use Signatures of a Bank Building. Preprint. ACEEE Summer Study on Energy Efficiency in Buildings.

Yudelson, J. (2007). Predicting the growth of green buildings using the "Diffusion of Innovations" theory. http://www.calrecycle.ca.gov/greenbuilding/design/guidelines.htm 


\subsection{Appendix A- Questionnaire}




\section{CBP Program Feedback \& Replication Questionnaire}

\section{Section 1: CBP Program Participation Information}

The questions in this section are designed to inform PNNL about CBP partner structure, motivations and objectives for implementing CBP measures.

1. What principal industry is your organization engaged in?

2. Did your organization participate in a new construction or retrofit project?

New Construction
Retroft Existing Bullding
Both

3. What phase of the CBP project are you currently in?
$\bigcirc$ Design phase
construction phase
Finished construction, but bullding not occupled
Finished construction, occupled bullaing
Other (please specity)

4. Did you participate in any other energy efficiency or sustainability programs before, during or after the CBP program?
Yes
$\mathrm{ONo}^{\mathrm{N}}$
O I don't know 


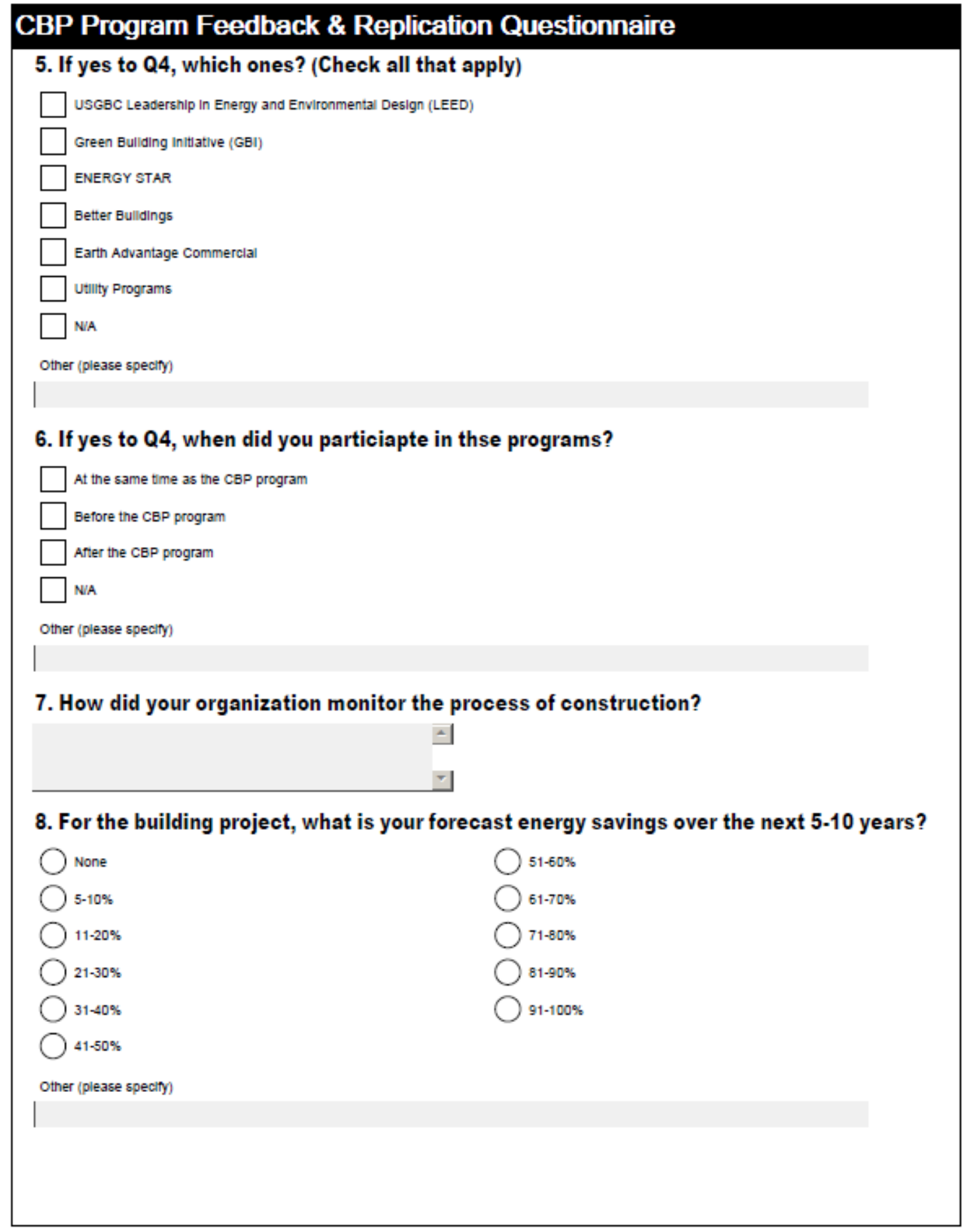

Page 2 


\section{CBP Program Feedback \& Replication Questionnaire}

9. Will specific building measures be implemented into the rest of your building portfolio? If so, what are the forecast energy savings portfolio-wide over the next $\mathbf{5 - 1 0}$ years?
None
5-10\%
51-60\%
$\mathrm{O}_{11-20 \%}$
(61-70\%
$\bigcirc_{21-30 \%}$
$71-80 \%$
31-40\%
(81-90\%
$\mathrm{C}^{41-50 \%}$
91-100\%
Other (please speciry)

10. For the building project, what is your forecast cost savings over the next 5-10 years?
None
$51-60 \%$
5-10\%
(61-70\%
$11-20 \%$
$71-80 \%$
$21.30 \%$
$81-90 \%$
$31-40 \%$
91-100\%
${ }^{41.50 \%}$
Other (please specily)
|

11. Will specific building measures be implemented into the rest of your building portfolio? If so, what is the forecast cost savings portfolio-wide over the next 5-10 years?
None
$51-60 \%$
5-10\%
(61-70\%
${ }_{11-20 \%}$
71-80\%
$21.30 \%$
(1-90\%
$31-40 \%$
(91-100\%
41.50\%
Other (please speciny)

| 


\section{CBP Program Feedback \& Replication Questionnaire}

12. In comparison to other investments, how does your organization prioritize investments in energy efficiency, such as those associated with the CBP program?

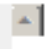

13. Did/will you receive any subsidies for investing in energy efficiency measures? If so, what type and from who? 


\section{CBP Program Feedback \& Replication Questionnaire}

\section{Section 2: Replication Information}

The questions in this section are designed to inform PNNL about specific replication strategies and outcomes of replicating CBP measures.

14. Will you install measures from the CBP project into the rest of your building portfolio?

Yes

No

O I don't know

Other (please specify)

Page 5 


\section{CBP Program Feedback \& Replication Questionnaire}

15. What Energy Efficient Measures (EEMs) from the CBP program have you implemented in other buildings? (check all that apply)

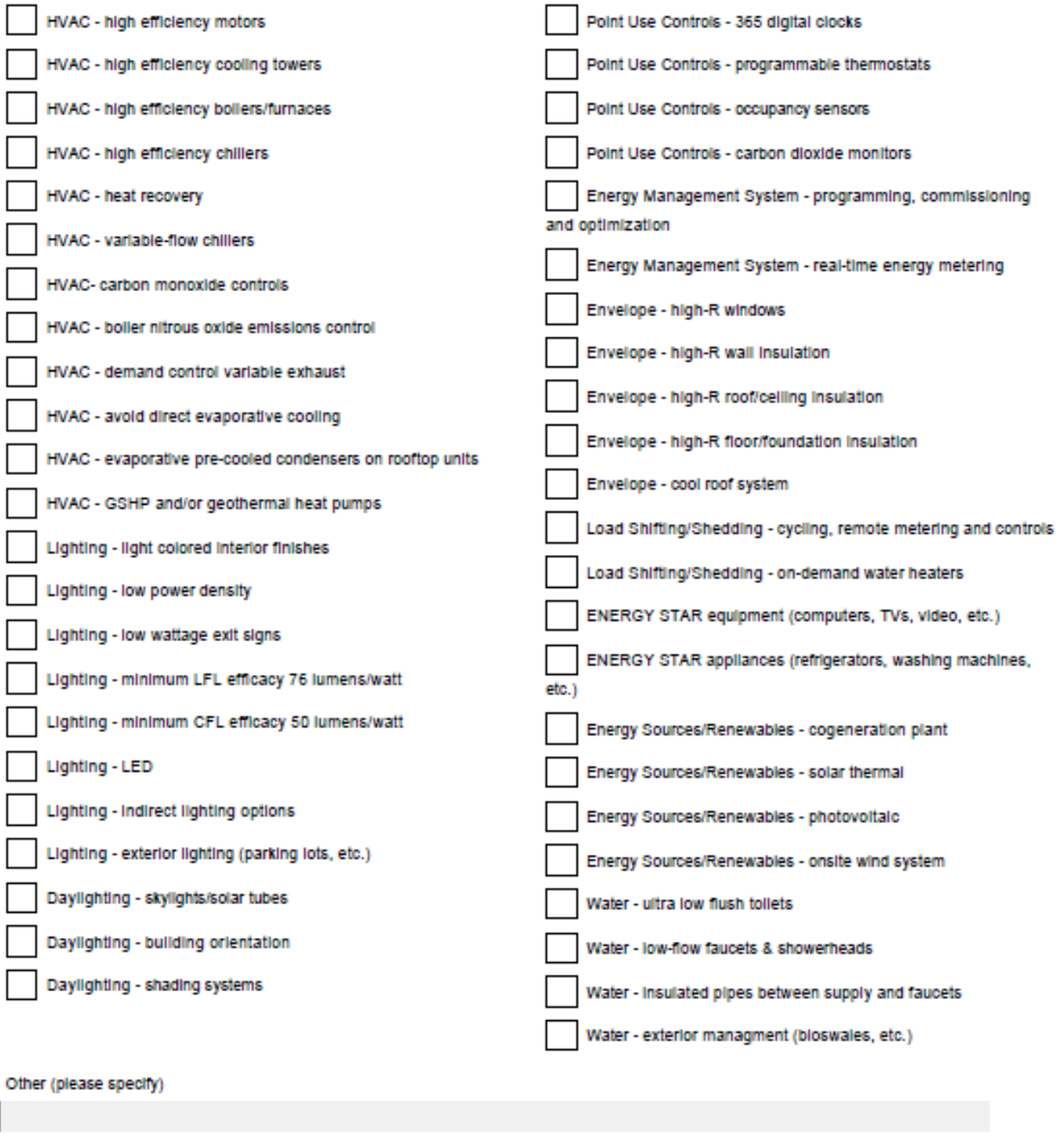




\section{CBP Program Feedback \& Replication Questionnaire}

16. What specific Energy Efficient Measures (EEMs) are you replicating? (unlike Q15, this gives you an opportunity to identify specific measures not identified above, or provide technical specifications such as wattage, $\mathbf{R}$-values, etc.)

17. Was your decision to replicate Energy Efficient Measures (EEMs) directly a result of lessons learned from the CBP program?

Yes

No

I don't know

18. What Energy Efficiency Measures (EEMs) provided the greatest energy savings?

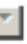

19. What Energy Efficiency Measures (EEMs) provided the greatest cost savings? 4 佂

20. How many buildings have you implemented CBP measures in?

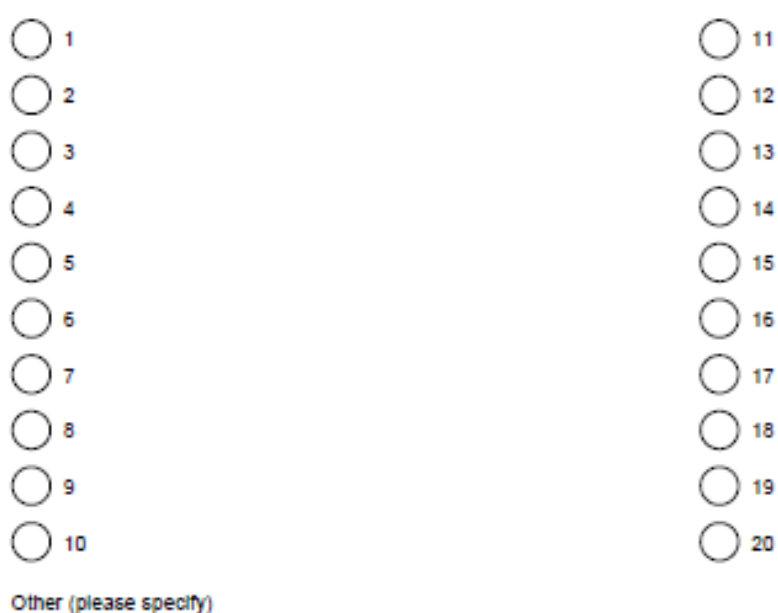

Other (please specify) 


\section{CBP Program Feedback \& Replication Questionnaire}

21. What is the total square footage of these buildings?

22. What is the total square footage of your entire building portfolio?

23. Do you use modeling or financial analysis software to determine what measures you implement into building construction or retrofits? If so, which ones?

$-1$

$+1$

24. When analyzing the economics of implementing CBP measures, what financial metrics do you use?

$\square$ simple payback

$\square$ Return on invesment (ROI)

$\square$ Time-horzon analysis

$\square$ Life-cycle cost analysis (LCCA)

$\square$ Savings-to-Investment ratio (SIR)

$\square$ Bulliding life-cycle cost assessment (BLCC)

Other (please speciny)

| 


\section{CBP Program Feedback \& Replication Questionnaire}

25. Besides energy reduction and cost savings, what are the benefits of replicating measures from the CBP program to your company? Can you rank your answers?

\begin{tabular}{|c|c|}
\hline Lower maintenance & N/A \\
\hline Increases employee productivity & NUA \\
\hline Increased number of Jobs & N/A \\
\hline Positlve medla & NIA \\
\hline Marketing opportunities & NUA \\
\hline Increased sales & N/A \\
\hline New market opportunitles & N/A \\
\hline Increased satety & NiA \\
\hline Increased comfort & N/A \\
\hline Decreased greenhouse gas emissions & NIA \\
\hline
\end{tabular}

26. Are the benefits in Q25 considered when deciding whether or not to replicate these measures? Which ones?

$$
\begin{aligned}
& 1 \\
& -1
\end{aligned}
$$




\section{CBP Program Feedback \& Replication Questionnaire}

\section{Section 3: Implementation/QA/Processes Development}

The questions in this section are designed to inform PNNL about the outcomes of replication, documentation processes and long term monitoring of CBP measures.

27. Do you have a company policy/procedure for implementing energy efficient measures?

Yes

No

Oidon't know

Other (please speciry)

28. Do you have an overall company sustainability protocol?
Yes
No
O I don't know
Other (please specity)

|

29. If yes to Q28, did that protocol influence your decision to participate in the CBP program?

$\bigcirc$ Yes

No

O I don't know

Other (please speciny)

30. Was the CBP project commissioned?
Yes
No
O idon't know
Other (please speciry)

| 


\section{CBP Program Feedback \& Replication Questionnaire}

31. Are all new and retrofit buildings commissioned?

Yes

No

O I don't know

Other (please specity)

32. How do CBP measures affect operations and maintenance (O\&M)?
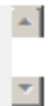

33. Do you have a documentation process for building design and energy efficiency? Do you use prototype plans? Who maintains the prototype plans?

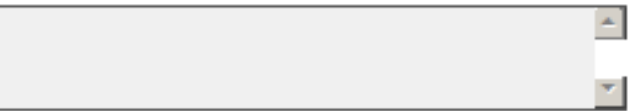

34. Will you share the prototype plans or documentation with PNNL?

Yes

No

Oidon't know

35. Do you have a system for monitoring and verification? If so, is this done in-house, buy contractors, etc.?

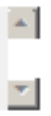

36. Do you monitor the performance of installed measures over time? If so, what tools do you use and for how long?

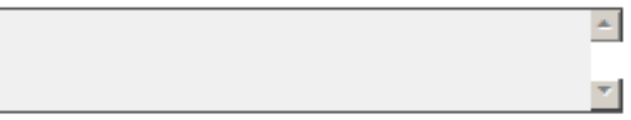

37. Are you getting the energy savings you expected? 